\title{
MicroRNA-129-5p modulates epithelial-to-mesenchymal transition by targeting SIP1 and SOX4 during peritoneal dialysis
}

\author{
Li Xiao ${ }^{1,3}$, Xun Zhou ${ }^{1,3}$, Fuyou Liu', Chun Hu', Xuejing Zhu', Ying Luo ${ }^{1}$, Ming Wang ${ }^{1}$, Xiaoxuan Xu', Shikun Yang ${ }^{1}$, \\ Yashpal S Kanwar ${ }^{2}$ and Lin Sun ${ }^{1}$
}

Peritoneal dialysis (PD) is the most readily feasible home-dialysis method for renal replacement therapy. However, repeated use of PD can lead to induction of mesothelial/epithelial-mesenchymal transition (MMT/EMT) and fibrosis, eventually leading to ultrafiltration failure and discontinuation of PD. MicroRNA-129-5p (miR-129-5p) is believed to be a potent downstream inhibitor of TGF- $\beta 1$ in renal fibrosis, but the effect of miR-129-5p on MMT/EMT relevant to PD is unknown. In this study, as determined by microRNA array analysis and confirmed by northern blot analysis and real-time PCR, we demonstrate that miRNA-129-5p is decreased in mesothelial cells isolated from effluent of patients having PD for more than 6 months extending to several years compared with those who have undergone PD for less than 6 months. The decreased expression of miR-129-5p was accompanied with alterations in EMT-related genes and the expression of respective proteins in vivo. In addition, in in vitro studies we noted that the expression of E-cadherin and claudin-1 were significantly reduced with increased cell migration in HMrSV5, a human peritoneal mesothelial cell line (HPMC), treated with TGF- $\beta 1$, whereas expression of vimentin, fibronectin and transcription factors SIP1 and SOX4 increased significantly, as assessed by real-time PCR, western blot analysis and immunofluorescence microscopy. Furthermore, alteration in EMTrelated genes and proteins were reversed by overexpression of miR-129-5p. No effect was observed in cells treated with miR-negative control. Meanwhile, inhibition of SIP1 and SOX4 with their respective siRNA also could decrease the expression of EMT-related genes and protein levels in HPMCs induced with TGF- $\beta 1$. Finally, we demonstrate that SIP1 can inhibit the promoter activity of E-cadherin while enhancing the promoter activity of vimentin. We also observed that miR-129-5p could directly target the 3'UTR of SIP1 and SOX4 genes, and repressed their post-transcriptional activities. These data suggest that there is a novel TGF- $\beta 1 /$ miR-129-5p/SIP-1 or SOX4 pathway that has a significant role in MMT and fibrosis in the setting of PD.

Laboratory Investigation (2015) 95, 817-832; doi:10.1038/labinvest.2015.57; published online 11 May 2015

Peritoneal dialysis (PD) is an alternative treatment for endstage renal disease that uses the peritoneal membrane (PM) as a permeable barrier for the exchange of nocuous substances and water. ${ }^{1,2}$ During PD, long-term exposure to bioincompatible PD solutions and episodes of infection cause damage to the PM, which then can lead to denudation of the mesothelial cells (MCs), submesothelial fibrosis and angiogenesis, eventually leading to ultrafiltration failure and discontinuation of $\mathrm{PD}^{2}$ Emerging evidence has indicated phenotypic conversion of MCs to mesenchymal cells. The mesothelial-to-mesenchymal transition (MMT) is an initial and reversible event leading to structural and functional peritoneal lining deterioration. ${ }^{3,4}$ Recent studies indicate that the MMT is a complex process, which is characterized by a loss of epithelial phenotype and acquisition of myofibroblast-like properties, ${ }^{5,6}$ and the cellular and molecular mechanisms and factors that participate in this process are not fully delineated.

TGF- $\beta 1$ is a potent inducer of epithelial-to-mesenchymal transition (EMT) in several tissues and organs. ${ }^{7-9}$ TGF- $\beta 1$ binds to its receptor and triggers Smad/non-Smad signaling pathways, which results in a profound molecular reprogramming, including the downregulation of the intracellular

\footnotetext{
${ }^{1}$ Department of Nephrology, Second Xiangya Hospital, Central South University, Changsha, Hunan, China and ${ }^{2}$ Departments of Pathology and Medicine, Northwestern University, Chicago, IL, USA

Correspondence: Dr L Sun, MD, PhD or Dr F Liu, MD, Department of Nephrology, Second Xiangya Hospital, Central South University, Changsha, Hunan 410011, China. E-mail: zndxsunlin@163.com or Ify2061@163.com

${ }^{3}$ These authors contributed equally to this work.
}

Received 2 October 2014; revised 9 February 2015; accepted 18 March 2015 
adhesion molecule E-cadherin and the upregulation of mesenchymal-associated molecules, such as, vimentin, fibronectin (FN), etc. ${ }^{7,8}$ TGF- $\beta 1$ is known to have a pathogenetic role in the MMT in states of PD dysfunction. ${ }^{1,10-12}$ However, the mechanism(s) by which TGF- $\beta 1$ induces MMT in PD dysfunction remains to be clearly defined.

MicroRNAs (miRNAs) are small 18-25-nucleotide noncoding RNAs that are believed to be involved in the modulation of gene expression by inducing mRNA degradation or repressing mRNA translation, ${ }^{13}$ and thus have a globalized role in a wide variety of biological functions, such as cellular proliferation, apoptosis, tumorigenesis, and fibrosis in various target organs. ${ }^{13-15}$ Recent studies indicate that miRNAs may contribute to the process of EMT in PD dysfunction ${ }^{10,16,17}$ as well as in development of fibrosis. ${ }^{18-20}$ For example, miR-30 and miR-589 have been reported to be associated with the MMT process and peritoneal fibrosis in certain models of $\mathrm{PD}^{10,16}$, suggesting that miRNA may $\mathrm{h}$ ave a critical role in the pathogenesis of TGF- $\beta$-induced fibrosis in PD.

To identify other miRNAs involved in the MMT/EMT of peritoneal MCs (PMCs), we employed miRNA array analyses of the PMCs from the effluent of PD patients. The results indicate that some miRNAs, including miR-129-5p, were downregulated in patients undergoing PD for more than 6 months when compared with those undergoing PD therapy for less than 6 months. We further demonstrate that miR-129-5p expression is notably decreased, which closely correlated with the development of MMT/EMT and peritoneal fibrosis in the PD patients. We also observed that overexpression of miR-129-5p in human PMCs (HPMCs) reversed the TGF- $\beta 1$-induced MMT/EMT phenotypic transformation cells and the expression of SIP1, a member of the zinc-finger E-box-binding (ZEB) homeobox factor family, as well as the sex-determining region Y-related high-mobility group box-4 gene (SOX4). In addition, we noted that miR-129-5p regulate promoter activity of E-cadherin and vimentin in HPMCs treated with TGF- $\beta 1$. Finally, we report that miR-129-5p could directly target the $3^{\prime}$ untranslated region (UTR) regions of SIP1 and SOX4 genes, and modulate their translational efficiency. From these data, we suggest that miR-129-5p could serve as a potential therapeutic target for the amelioration of peritoneal fibrosis in PD.

\section{MATERIALS AND METHODS}

\section{Peritoneal Equilibrium Test (PET)}

PET measurements were carried out as previously reported. $^{21,22}$ Briefly, a $2.5 \%$ glucose exchange was performed overnight using a PD patient's standard dwell volume. The abdomen cavity was drained for over $20 \mathrm{~min}$, following which $2.5 \%$ dextrose dialysate ( $2 \mathrm{l})$ was instilled into the peritoneal cavity. A $10-\mathrm{ml}$ sample was removed at $4 \mathrm{~h}$ to determine the urea, creatinine, and glucose levels. PM transport function was designated as high, high average, low average or low transporter, as classified previously. ${ }^{21,22}$

\section{Human PMCs (HPMCs)}

Sixteen patients were enrolled for the continuous ambulatory PD (CAPD), including eight patients who received CAPD for 'more' than 6 months (from 6 to 50 months) and were designated as the PD >6 months group, and eight patients who received CAPD for 'less' than 6 months and were designated as the PD-start group. The study was approved by the Institutional Review Board and Ethics Committee of The Second Xiangya Hospital, Central South University, China. All of the participants had signed the informed consent form. HPMCs were harvested from the effluents of PD patients before the first episode of peritonitis occurred. The HPMCs were isolated using low-speed (1500 r.p.m.) centrifugation, washed with DMEM, cultured in DMEM containing L-glutamine supplemented with $15 \% \mathrm{FBS}, 0.5 \mu \mathrm{g} / \mathrm{ml}$ insulin, $5 \mu \mathrm{g} / \mathrm{ml}$ transferrin, and $1 \mu \mathrm{g} / \mathrm{ml}$ hydrocortisone in humidified air with $5 \% \mathrm{CO}_{2}$ at $37^{\circ} \mathrm{C}$. Nonadherent cells were removed the next day with two brief washes with DMEM, and the adherent cells were incubated in fresh culture medium. The cells were allowed to reach confluence in 7-10 days, and then they were split and seeded onto two to three cultured flasks. After achieving $80 \%$ confluency, the cells were used for various experiments.

\section{miRNA Microarray Analyses}

Total RNA was extracted from HPMCs using TRIzol reagent (Invitrogen, Carlsbad, CA, USA) as per the manufacturer's instruction, and miRNA microarray was performed at Kangcheng BioCorp (Shanghai, China). Briefly, Total RNA was purified and hybridized onto the miRCURY LNA Array (v.11.0), which contains probes of over 1700 unique miRNAs based on the miRBase version 11.0 release of hsa, mmu \& rno array (online at http://microrna.sanger.ac.uk). The intensity values of the microarray data were subjected to GenePix pro V6.0 for subtraction of background values and normalization, followed by mean summarization. A list of miRNA candidates was generated based on their differential expression between the two populations of RNA from PD patients ( $<6$ months PD $v s>6$ months).

\section{Culture of MC Line}

HMrSV5 (a human peritoneal mesothelial cell line) was obtained from Dr Pierre Ronco (Tenon Hospital, Paris). ${ }^{23,24}$ Cells were maintained in DMEM/F12 medium (Invitrogen) containing $10 \%$ fetal bovine serum, and incubated at $37^{\circ} \mathrm{C}$ in a humidified incubator with 5\% $\mathrm{CO}_{2}$. After achieving $80 \%$ confluency, the cells were cultured in serum-free medium in the presence or absence of $5 \mathrm{ng} / \mathrm{ml}$ of TGF- $\beta 1$ (R\&D Systems, Minneapolis, MN). In various combinations, the cells were transfected with pre-miR-129-5p or miRNA-negative control (miR-neg-ctrl) (Life Technologies, CA, USA), or SIP1-siRNA and SOX4-siRNA (Santa Cruz Biotechnology, TX, USA), or with pBK-CMV-hNHERF2 plasmid (Entrez Gene: SIP1, Plasmid \#47801 SIP1), a mammalian cell expression plasmid (Addgene, Cambridge, MA, USA), or pWPXL-Sox4 plasmid 
(Entrez Gene: SOX4, Plasmid \#36984) from Addgene. For transfection, the Lipofectamine 2000 kit was used following the manufacturer's instructions (Invitrogen). The cells were then used for various expression studies and assays.

\section{TaqMan Reverse Transcription-PCR (RT-PCR) Studies}

For measurement of miR-129-5p expression, a RT reaction was performed using the TaqMan MicroRNA Reverse Transcription Kit. Three $\mu \mathrm{l}$ of cDNA products were used for the measurement of miR-129-5p by employing the TaqMan MicroRNA Assays-miR-129-5p kit (Life Technologies) as per the manufacturer's instructions. For mRNA expression of various genes, total RNA (500 ng) was used for RT and the cDNA was synthesized as described. ${ }^{25}$ The mRNA expression of SIP1, SOX4, E-cadherin, claudin-1, vimentin, and FN was detected by TaqMan gene expression assays using Real-time PCR system 7300 (Applied Biosystems, Life Technologies). ${ }^{26-29}$ The expression of miR-129-5p and of various genes were normalized to $\beta$-actin and U6snRNA. The PCR primers used were as follows: E-cadherin sense: $5^{\prime}$-GTC ACTGACACCAACGATAATCCT- ${ }^{\prime}$ and antisense: $5^{\prime}$-TTTC AGTGTGGTGATTACGACGTTA-3', vimentin sense: $5^{\prime}$-TTG AACGCAAAGTGGAATC- $3^{\prime}$ and antisense: $5^{\prime}$-AGGTCAGG CTTGGAAACA- ${ }^{\prime}$, claudin-1 sense: $5^{\prime}$-CCAGTCAATGCCA GGTACGAAT- ${ }^{\prime}$ ' and antisense: $5^{\prime}$-TTGGTGTTGGGTAAGA GGTTGTT-3', FN sense: 5'-TGGAGGAAGCCGAGGTTT-3' and antisense: $5^{\prime}$-CAGCGGTTTGCGATGGTA-3', $\beta$-actin sense: $5^{\prime}$-CCTTCCTGGGCATGGAGTC- $3^{\prime}$ and antisense: 5'-GAGGAGCAATGATCTTGATCTTC-3', SOX4 sense: 5'-GTGAGCGAGATGATCTCGGG-3' and antisense: $5^{\prime}$-CA GGTTGGAGATGCTGGACTC-3' and SIP1 sense: 5'-CCCTT CTGCGACATAAATACA-3' and antisense: 5'-TGTGATTC ATGTGCTGCGAGT-3'.

\section{Northern Blot Analysis of miRNAs}

To confirm the miRNA-129-5p expression in cells from PD patients, northern blotting procedures were performed, as described previously. ${ }^{30,31}$ Briefly, $50 \mu \mathrm{g}$ of low-molecular weight RNA was subjected to denaturing $10 \%$ polyacrylamide gel electrophoresis, transferred to a PVDF membrane (Amersham, NJ, USA), and probed. The probes used were $\gamma$-32 P-ATP (PerkinElmer Life Sciences, Akron, OH, USA) end labeled of locked nucleic acid (LNA)-modified miR-129$5 p$ oligonucleotide from Exiqon (Woburn, MA, USA). The northern blot analysis of miRNAs was carried out following their quantification using National Institutes of Health Image J version $1.42 \mathrm{q}$ software, as described previously. ${ }^{31}$

\section{Western Blot Analyses}

Protein expression was assessed by western blot analysis. Protein $(50 \mu \mathrm{g})$ samples were resolved by $10 \%$ SDS-PAGE and transferred to PVDF membranes, then probed with various primary antibodies against E-cadherin, claudin-1, and vimentin (Santa Cruz Biotechnology); FN (Sigma-Aldrich, St Louis, MO, USA); SIP1 and SOX4 (Abcam Trading
Company, Shanghai, China). After incubating with an appropriate secondary antibody, the protein expression was detected by western blot analysis, as described previously. ${ }^{27-29}$ $\beta$-Actin (Santa Cruz Biotechnology) was used as an internal control.

\section{Immunofluorescence Studies}

HPMCs were grown on coverslips, washed twice with PBS, fixed in 4\% paraformaldehyde for $20 \mathrm{~min}$, and permeabilized using $0.1 \%$ Triton $\mathrm{X}-100$. The antibodies used were as follows: anti-E-cadherin (1:100 dilution), anti-vimentin (1:100) from Santa Cruz Biotechnology; anti-SIP1 (1:100), and anti-SOX4 (1:100) from Abcam. The antibodies were diluted in a blocking buffer and cells were incubated with them overnight at $4{ }^{\circ} \mathrm{C}$, followed by incubation with FITClabeled secondary antibody (Santa Cruz Biotechnology) for $2 \mathrm{~h}$ at $22^{\circ} \mathrm{C}$. They were then examined using a UV fluorescence microscope. The intensity of fluorescence was analyzed by image analysis software (Path, QC, Logene Biological Medical Engineering) as described in (ref. 31).

\section{Cell Migration Studies}

For cell migration assays, trypsinized HPMCs were seeded onto 12-well plates. A wound was created by scratching the cell culture with a pipette tip. The status of the wound was monitored for several hours after treating the cells with TGF- $\beta 1$ with or without transfection of pre-miR-129-5p. The wound width in the cell culture was measured at the termination of the experiments, as described in previous publications. ${ }^{32,33}$

\section{Promoter Activity Assay}

Promoter activity assays were carried out using a luciferase system. A E-cadherin-luciferase reporter was constructed by cloning the human E-cad promoter fragment spanning -420 to +32 from the transcription start site upstream of the luciferase segment in the pGL3 vector (Promega, Madison, WI, USA), as described, ${ }^{34}$ and designated as pGL3-E-cad vector. Briefly, the promoter fragment was first cloned into PCR II vector by PCR using oligonucleotide sense primer: 5'-AGAACCGTGCAGGTCCCATAA-3' and antisense primer: $3^{\prime}$-AACTGACTTCCGCAAGCTCAC-5' and the genomic DNA from HPMCs that served as the template. Following cloning, its sequence was confirmed to ensure that there were no mutations. The promoter fragment was then subcloned into pGL3 vector (Promega). To construct the human vimentin promoter luciferase reporter plasmid (VimPro), a 1.5 -kb fragment of human vimentin $5^{\prime}$-upstream region was cloned in the EcoRI-BamHI site of the firefly luciferase reporter plasmid pGL3 (Promega). ${ }^{35}$ Briefly, the promoter $(-1416$ to $+85 \mathrm{bp})$ of human vimentin $5^{\prime}$-upstream region was cloned into PCR II vector and amplified using the sense primer: 5'-AATTCCTTTTGAAAACAGAACCTATCATT-3' and the antisense primer: $5^{\prime}$-GAAGAGGGAAGAGGGGGGT GGGTGTGGGT-3'. Following confirmation of the sequence, 
the fragment then was subcloned at the EcoRI-BamHI site of the firefly luciferase reporter plasmid pGL3 as described previously. ${ }^{35,36}$ For the luciferase assay, pGL3-E-cad and vimPro constructs were then transiently transfected into HPMCs in a 24-well plate that were serum starved for $18 \mathrm{~h}$ prior to treatment with TGF- $\beta 1$, or co-transfected with SIP plasmid or pre-miR-129-5p siRNA. After $24 \mathrm{~h}$, luciferase activity was measured using the Dual Luciferase Reporter Assay System (Promega) following the manufacturer's instructions. The luciferase activities were subsequently normalized with $\beta$-galactosidase activity where cells were co-transfected with pSVb-galactosidase vector (pSVb) (Promega) as in (ref. 36).

\section{Luciferase Reporter Assay}

For construction of the $3^{\prime}$ UTR of SIP1 and SOX4 reporter plasmids, SIP1 and SOX4 3'UTR segments were amplified by PCR. They were then subcloned into pGL3 luciferase vector (Promega), as described previously, ${ }^{28,29}$ and the plasmids were designated as pGL3-SIP1-wt or pGL3-SOX4-wt. Mutations in SIP1 and SOX4 3'UTR were then created using the pGL3SIP1-wt or pGL3-SOX4-wt as PCR templates while replacing four nucleotides in the miR-129-5p-binding site using a QuikChange Site-Directed Mutagenesis kit (Stratagene, La Jolla, CA, USA). These constructs were designated as pGL3SIP1-mut or pGL3-SOX4-mut, as previously reported. ${ }^{28,29}$ For luciferase reporter analysis, HMrSV5 cells were transfected with the reporter constructs as indicated above premiR-129-5p with or without TGF- $\beta 1$ treatment. Following $48 \mathrm{~h}$ of transfection, luciferase activity was measured using a Dual-Glo Luciferase Reporter Assay Kit (Promega) as described previously. ${ }^{28,29}$

\section{Statistical Analysis}

Data are expressed as the mean \pm s.e.m. One-way ANOVA was performed to assess the statistical analysis. $P$-values $<0.05$ were considered statistically significant.

\section{RESULTS}

\section{Mir-129-5p was Downregulated in the PMCs from the Effluent of PD Patients, Which Negatively Correlated with the MMT Transformation and the Expression of SIP1 and SOX4}

Average duration of dialysis in the PD-start group was $3.90 \pm 1.79$ months and $19.33 \pm 11.82$ months for the PD $>6$ months group $(P<0.01)$. There are no significant differences in other clinical characteristics, including gender, age, BMI, renal failure cause, and creatinine ratio (dialysis to plasma), at $4 \mathrm{~h}$ in a peritoneal equilibrium function test between PD-start and PD $>6$ months groups (Table 1). By miRNA array analysis, expression of 91 miRNAs was noted to be dysregulated in the cultured PMCs from the effluent of PD patients. Among them included $33 \mathrm{miRs}$ upregulated and 58 miRs downregulated in the PMCs from the PD patients having dialyses over 6 months compared with the PD-start group (Tables 2 and 3). The miR-129-5p was found to be
Table 1 Clinical characteristics of patients in each group

\begin{tabular}{|c|c|c|c|}
\hline & $\begin{array}{l}\text { PD-start } \\
\text { group }\end{array}$ & $\begin{array}{c}\text { PD }>6 \text { month } \\
\text { group }\end{array}$ & $P$-value \\
\hline Total number of patients ( $n$ ) & 8 & 8 & \\
\hline Males $(n)$ & 4 & 4 & \\
\hline Females $(n)$ & 4 & 4 & $>0.05$ \\
\hline Age (years) & $55.30 \pm 8.90$ & $56.30 \pm 5.82$ & \\
\hline BMI $\left(\mathrm{kg} / \mathrm{m}^{2}\right)$ & $23.50 \pm 3.55$ & $22.92 \pm 3.24$ & $>0.05$ \\
\hline \multicolumn{4}{|l|}{ Renal failure cause } \\
\hline Chronic glomerulonephritis ( $n$ ) & 5 & 4 & \\
\hline Diabetic nephropathy (n) & 1 & 2 & \\
\hline Hypertensive nephropathy ( $n$ ) & 2 & 2 & \\
\hline Dialysis duration (months) & $3.90 \pm 1.79$ & $19.33 \pm 11.82$ & $<0.01$ \\
\hline \multicolumn{4}{|l|}{ Peritoneal equilibrium test } \\
\hline $\mathrm{D} / \mathrm{PCr}(4 \mathrm{~h})$ & $0.69 \pm 0.15$ & $0.71 \pm 0.25$ & $>0.05$ \\
\hline High (n) & 1 & 2 & \\
\hline High average $(n)$ & 3 & 2 & \\
\hline Low average $(n)$ & 4 & 4 & \\
\hline Low $(n)$ & 0 & 0 & \\
\hline
\end{tabular}

downregulated nearly ninefold in the PMCs from the effluent of patients having PD $>6$ months (Figure 1a). The differential expression of miR-129-5p in PMCs from the effluent of PD patients was further validated by northern blot analyses and TaqMan real-time PCR (Figure $1 \mathrm{~b} \mathrm{B1}$ and B2).

At the same time, the expression of MMT/EMT-related genes and proteins was also altered. As shown in Figure 1c $\mathrm{C}$, $\mathrm{C} 2,1 \mathrm{~d}$ and 1e E1, E2, the mRNA and protein expression of E-cadherin significantly decreased in the PMCs from the effluent of PD $>6$ months patients, as compared with that from PD-start patients, whereas that of mesenchymal markers, such as vimentin and FN expression, increased. A negative correlation between miR-129-5p expression and that of vimentin and FN was seen, suggesting that miR-129-5p may be involved in the MMT process during PD.

Next, we investigated the expression of SIP1 and SOX4 transcription factors, as they may be the predicted targets of miRNA-129-5p by analysis of the 3'-UTR sequence using biological analysis software (www.microrna.org). These factors have been reported to have an important role in the EMT process. As expected, both mRNA and protein expression of SIP1 and SOX4 were increased in the PMCs from the effluent of the $\mathrm{PD}>6$ months group (Figure 1e E3), which positively correlated with the MMT transformation, and correlated with the expression of miR-129-5p. Moreover, an upregulated level 
Table 2 Upregulated microRNAs in PMCs from effluents of PD patients

\begin{tabular}{llll}
\hline miR ID & Fold change & miR ID & Fold change \\
\hline hsa-miR-146b-5p & 1.511596907 & hsa-miR-181a & 1.976029581 \\
hsa-miRPlus-E1066 & 2.51784185 & hsa-miRPlus-E1225 & 1.547911548 \\
hsa-miR-152 & 2.515094014 & hsa-miR-768-3p & 1.994051822 \\
hsa-let-7i & 1.753991528 & hsa-miR-23a & 1.720172866 \\
hsa-miR-26a & 1.796862942 & hsa-miRPlus-E1168 & 3.579545455 \\
hsa-miR-30e & 1.609776609 & hsa-miRPlus-E1234 & 2.415971126 \\
hsa-miR-923 & 2.919836761 & hsa-miR-193a-3p & 1.786047914 \\
hsa-miR-142-5p & 6.46627566 & hsa-miR-381 & 1.571759968 \\
hsa-miR-29c & 1.684491979 & hsa-miR-191 & 1.581974901 \\
hsa-miR-195 & 3.265361795 & hsa-miR-19b & 1.598804421 \\
hsa-miR-30a & 1.506479992 & hsa-miR-101 & 2.121212121 \\
hsa-miR-148b & 2.021994135 & hsa-miRPlus-C1115 & 2.40412813 \\
hsa-miR-142-3p & 3.854761537 & hsa-miRPlus-E1038 & 1.575815077 \\
hsa-miR-374a & 1.616047609 & hsa-miR-335 & 1.622201559 \\
hsa-miR-574-3p & 1.72550213 & hsa-miR-19a & 1.549112676 \\
hsa-miR-584 & 1.590380022 & hsa-miR-874 & 2.192191535 \\
hsa-miRPlus-E1141 & 1.855575049 & & \\
\hline & & & \\
\hline
\end{tabular}

of TGF- $\beta 1$ was also observed in effluent of the PD $>6$ months group, as assessed by ELISA methods (Figure 1f).

\section{TGF- $\beta 1$ Suppressed the Levels of miR-129-5p While Enhancing that of the SIP1 and SOX4 in HPMCs}

Real-time PCR showed that the expression of miR-129-5p decreased in HPMCs incubated with $5 \mathrm{ng} / \mathrm{ml} \mathrm{TGF-} \beta 1$ for $12 \mathrm{~h}$ (Figure 2a A1), and it was further suppressed in a timedependent manner. The change in the expression paralleled to the decreased expression of E-cadherin (Figure 2a A2) and claudin-1 mRNA (Figure 2a A3). The expression of vimentin (Figure 2a A4) and FN (Figure 2a A5) increased in a timedependent manner in HPMCs following TGF- $\beta 1$ treatment. Expression of both SIP 1 (Figure 2a A6) and SOX4 mRNA (Figure 2a A7) also significantly increased in the HPMCs treated with TGF- $\beta 1$, and peaked at $48-72 \mathrm{~h}$. Similar results were also seen in their protein expression levels (Figure $2 \mathrm{~b}$ and c).

\section{Overexpression of miR-129-5p Blocked MMT Transformation in HPMCs Treated with TGF- $\beta 1$}

To verify the precise role of miR-129-5p, expression of E-cadherin and vimentin was induced with TGF- $\beta 1$. The premiR-129-5p was transfected into HPMCs and then exposed to TGF- $\beta 1$. The results showed that overexpression of miR-129$5 p$ significantly reversed the TGF- $\beta 1$-reduced miRNA- $129-5 p$ expression, and there was no change seen in that treated with
Table 3 Downregulated microRNAs in PMCs from effluents of PD patients

\begin{tabular}{|c|c|c|c|}
\hline miR ID & Fold change & $\operatorname{miR} I D$ & Fold change \\
\hline hsa-miR-638 & 0.12995774 & hsa-miRPlus-E1013 & 0.557412989 \\
\hline hsa-miR-887 & 0.344830655 & hsa-miRPlus-E1013 & 0.557412989 \\
\hline hsa-miRPlus-D1116 & 0.276039331 & hsa-miRPlus-A1056 & 0.305602716 \\
\hline hsa-miRPlus-E1065 & 0.432457926 & hsa-miR-668 & 0.459077579 \\
\hline hsa-miRPlus-E1063 & 0.108676902 & hsa-miR-18b & 0.667155425 \\
\hline hsa-miR-585 & 0.008474804 & hsa-miR-302c & 0.37485656 \\
\hline hsa-miRPlus-D1036 & 0.116578778 & hsa-miRPlus-E1271 & 0.661862752 \\
\hline hsa-miRPlus-E1108 & 0.349294355 & hsa-miRPlus-F1187 & 0.362256339 \\
\hline hsa-miR-665 & 0.386159319 & hsa-miR-340 & 0.617657776 \\
\hline hsa-miRPlus-E1088 & 0.327549335 & hsa-miR-519d & 0.488210082 \\
\hline hsa-miRPlus-F1159 & 0.23318974 & hsa-miR-424 & 0.539301273 \\
\hline hsa-miRPlus-F1059 & 0.35227894 & hsa-miRPlus-E1045 & 0.085989973 \\
\hline hsa-miR-1264 & 0.653599292 & hsa-miRPlus-F1231 & 0.417888563 \\
\hline hsa-miRPlus-F1065 & 0.084296912 & hsa-miR-615-3p & 0.342130987 \\
\hline hsa-miR-1290 & 0.643846245 & hsa-miR-203 & 0.489369501 \\
\hline hsa-miRPlus-F1029 & 0.500866436 & hsa-miR-642 & 0.587843242 \\
\hline hsa-miRPlus-E1035 & 0.340330298 & hsa-miRPlus-E1202 & 0.351906158 \\
\hline hsa-miR-130b & 0.620431567 & hsa-miR-1285 & 0.559024359 \\
\hline hsa-miR-654-3p & 0.549258936 & hsa-miR-185 & 0.099529014 \\
\hline hsa-miR-197 & 0.595691616 & hsa-miR-129-5p & 0.11153682 \\
\hline hsa-miR-939 & 0.460133901 & hsa-miR-589 & 0.576422287 \\
\hline hsa-miR-1274a & 0.581932299 & hsa-miR-888 & 0.41211142 \\
\hline hsa-miRPlus-E1247 & 0.184014674 & hsa-miRPlus-E1170 & 0.556634372 \\
\hline hsa-miRPlus-F1063 & 0.609677419 & hsa-miRPlus-E1024 & 0.652822229 \\
\hline ebv-miR-BHRF1-2 & 0.015710096 & hsa-miR-15b & 0.562997796 \\
\hline hsa-miR-138-1 & 0.628589773 & hsa-miR-634 & 0.482134589 \\
\hline hsa-miRPlus-A1098 & 0.122377622 & hsa-miR-602 & 0.474924201 \\
\hline ebv-miR-BART2-3p & 0.364387259 & hsa-miR-202 & 0.017106549 \\
\hline hsa-miRPlus-E1253 & 0.634025019 & hsa-miRPlus-B1114 & 0.622996658 \\
\hline
\end{tabular}

miR-negative control (Figure 3a). In addition, the inhibitory effect of TGF- $\beta 1$ on the mRNA expression of the E-cadherin (Figure 3b B1) and claudin-1 (Figure 3b B2) was also blocked partially in cells transfected with pre-miR-129-5p, whereas opposite results were observed for vimentin (Figure 3b B3) and FN expression (Figure 3b B4). Similar results were seen in their protein expression by western blot analyses (Figure 3c and d). The immunofluorescence staining of E-cadherin was significantly decreased in the membranes of HPMCs stimulated with TGF- $\beta 1$, whereas the signal intensity was restored in cells transfected with pre-miR-129-5p (Figure 3e, left panels and Figure $3 \mathrm{f} \mathrm{F1).} \mathrm{On} \mathrm{the} \mathrm{other} \mathrm{hand,} \mathrm{over-}$ expression of pre-miR-129-5p significantly inhibited TGF- $\beta 1$ - 
a

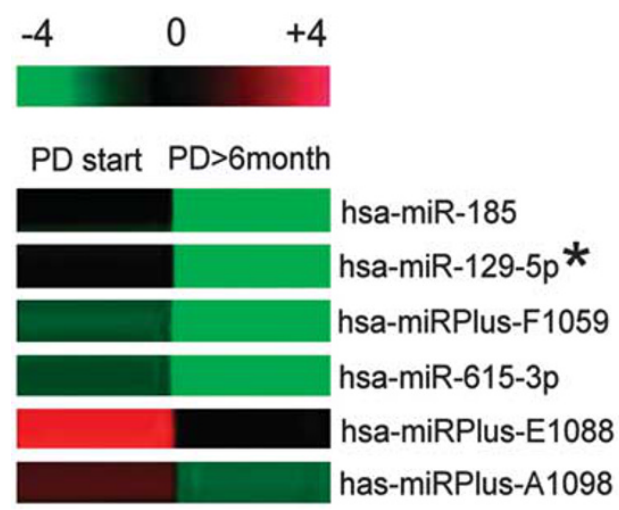

b

B1
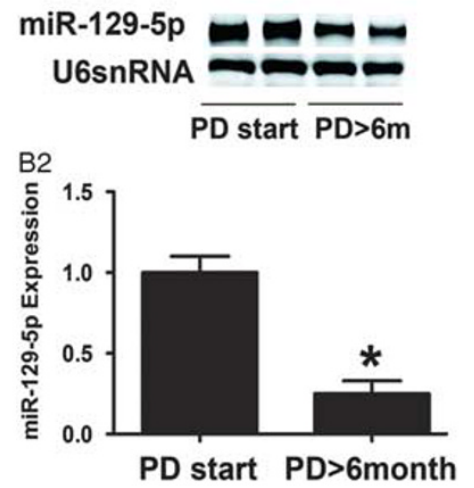

C

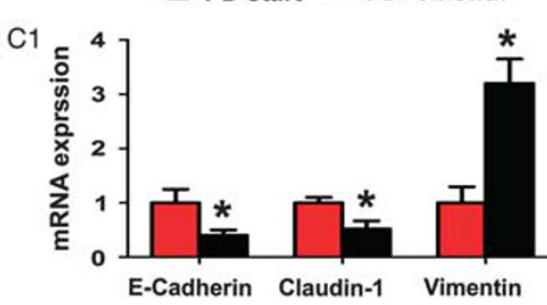

C2

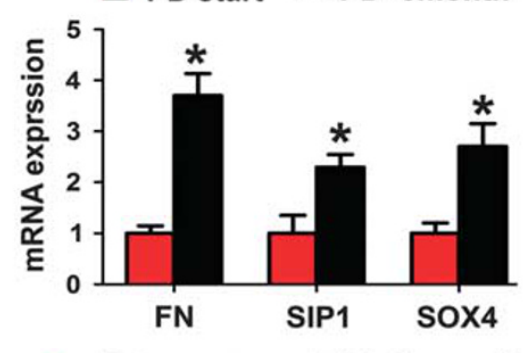

DD start $=\mathrm{PD}>6$ month

e

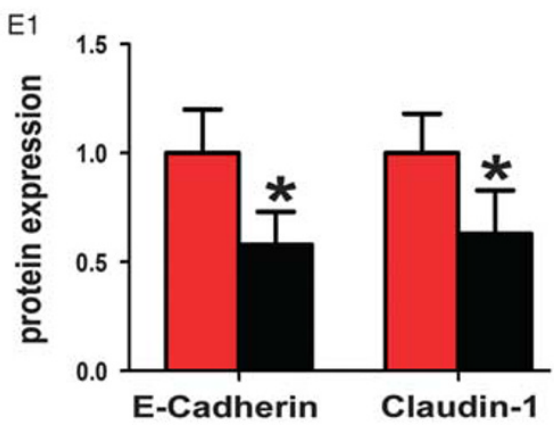

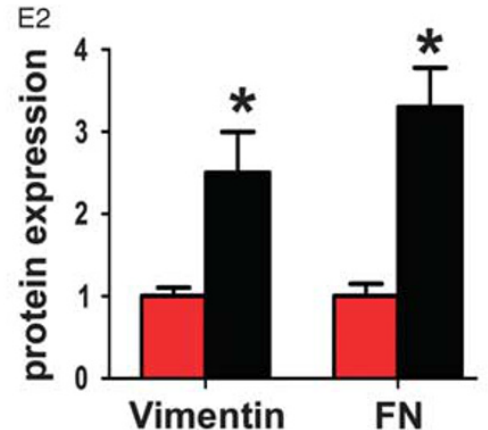

E3

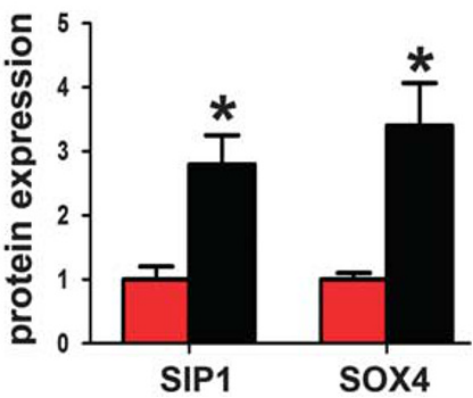

f

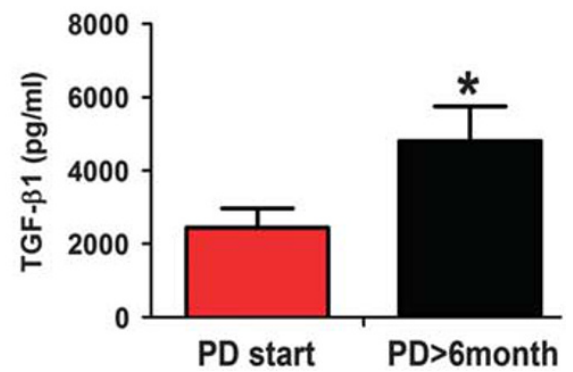

\section{PD start $-\mathrm{PD}>6$ month}

Figure 1 miR-129-5p, epithelial-mesenchymal transition-related genes, SIP1, SOX4, and TGF- $\beta 1$ expression in the mesothelial cells isolated from effluent of patients with peritoneal dialysis (PD). (a) MicroRNA (miRNA) expression profiling in the mesothelial cells isolated from effluent of patients with PD, as detected by miRNA array analyses, a decreased expression of miR-129-5p was seen (asterisks). (b, B1) Northern blot analysis showed that miR-129-5p expression decreased in the PD patients (PD $>6$ months) as compared with that of the control group (PD $<6$ months). There was no change in U6snRNA expression, which served as an internal control. (B2) The bar graph represents the summary of the messenger RNA (mRNA) expression of miR-129-5p from northern blot analysis. (c) The bar graph represents the summary of the mRNA expression of E-cadherin, claudin-1, vimentin (C1), fibronectin, SIP1, and SOX4 (C2) in the cells by real-time PCR. (d) Expression profiling of their protein levels as assessed by western blot analysis. (e, E1-E3) The bar graphs represent the density of relative bands depicted by western blot analyses. (f) TGF- $\beta 1$ expression in the effluent of PD patients by an enzymelinked immunosorbent assay. Values are the mean \pm s.e.m., $n=4,{ }^{*} P<0.01$ vs control (PD $<6$ months). 

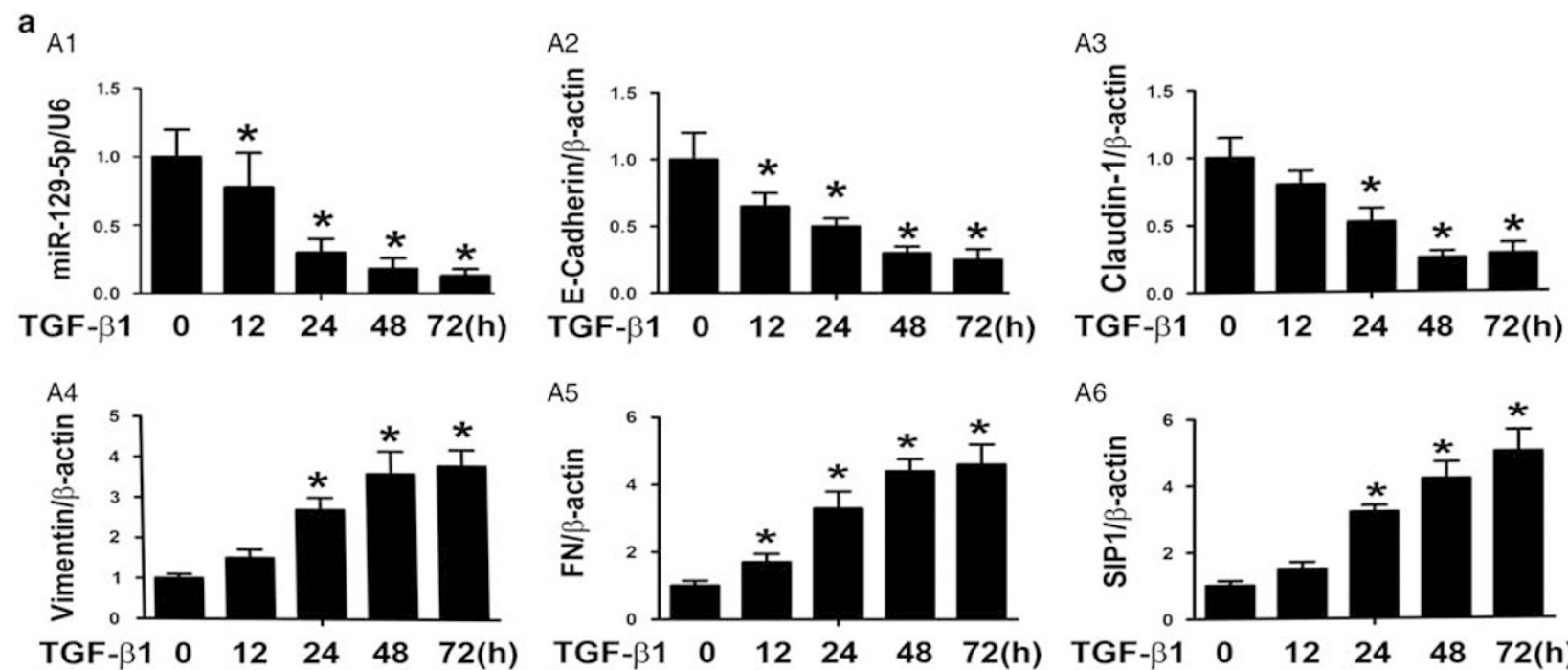

A5

A6
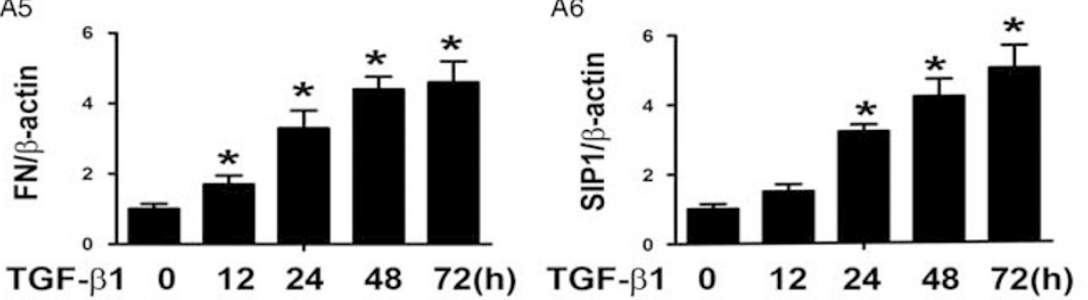

A7
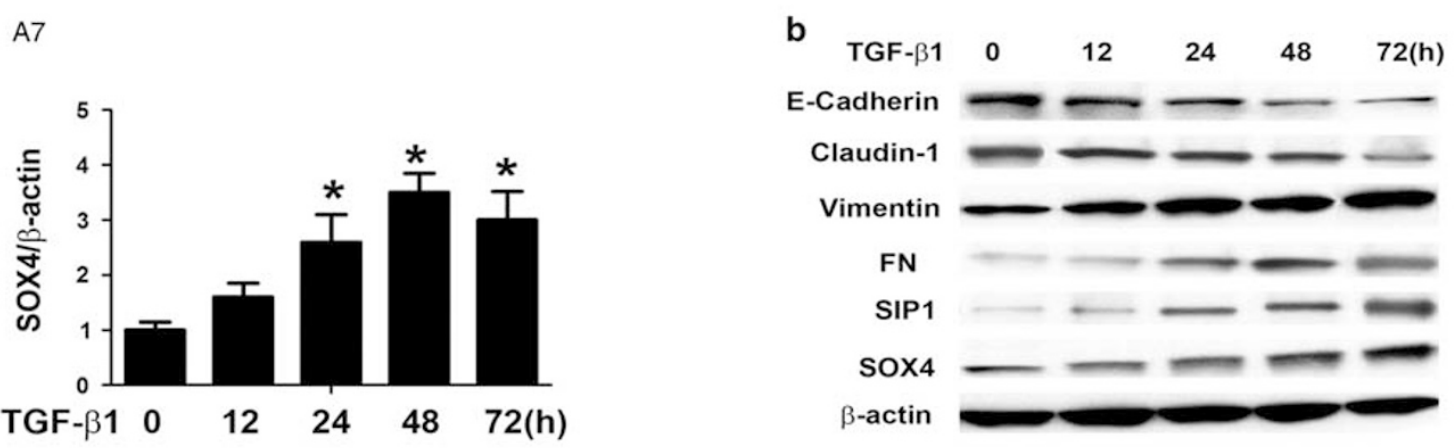

c $_{\text {C1 }}$
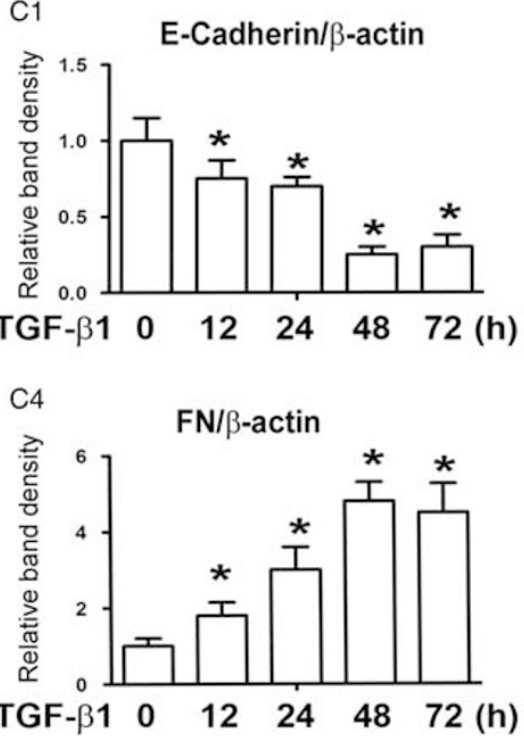

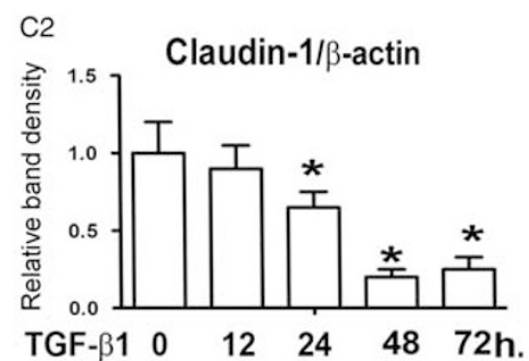

C3

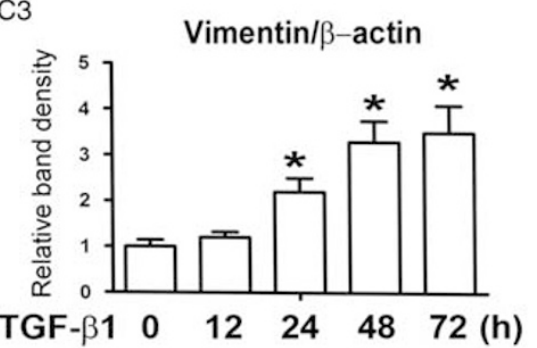

C5

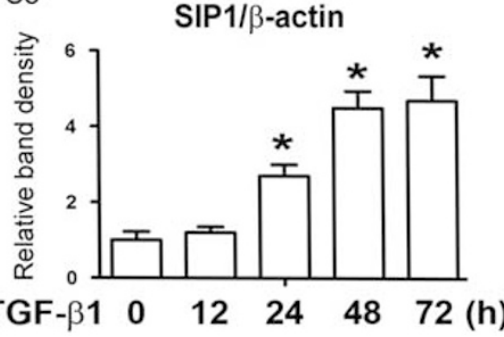

C6

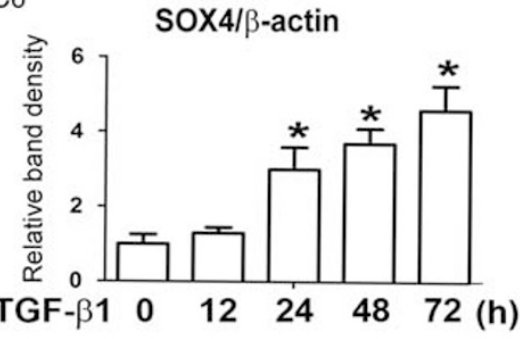

Figure 2 Expression of epithelial-mesenchymal transition-related genes, SOX4, and SIP1 in human peritoneal mesothelial cell lines (HPMCs) induced by TGF- $\beta 1$. (a) The bar graph represents the summary of the results by real-time PCR. (A1) An overt decrease in messenger RNA expression of miRNA-129$5 p$ was observed in HPMCs, a human peritoneal mesothelial cell line, following treatment with TGF- $\beta 1$. Real-time PCR showed that E-cadherin (A2) and Claudin-1(A3) expressions were significantly decreased in a time-dependent manner in HPMCs treated with TGF- $\beta 1$, whereas expression of vimentin (A4) and fibronectin (A5), SIP1 (A6) and SOX4 (A7) were upregulated. (b) Western blot assays showed the expression of E-cadherin, claudin, vimentin, fibronectin (FN), SIP1, and SOX4 proteins in HPMCs induced with TGF- $\beta 1$. (c, C1-C6) The bar graphs representing the western blot relative band densities from Figure $7 \mathrm{~b}$. Values are the mean \pm s.e.m., $n=3,{ }^{*} P<0.01$ vs control. 
induced vimentin expression (Figure 3e, right panels and Figure $3 \mathrm{f} \mathrm{F2}$ ). There were no differences in cells transfected with miR-negative control compared with the control group. Since cell migration has been described to be modulated by the EMT process, the studies were performed to further understand the effect of miR-129-5p on cell migration in HMPCs. We observed that the overexpression of miR-129-59 significantly dampened the TGF- $\beta 1$-induced HMPC migration, as shown in Figure $3 \mathrm{~g}$ and $\mathrm{h}$. In other words, treatment of cells with TGF- $\beta 1$ leads to increased
HMPC migration, whereas miR-129-59 treatment decreases cell migration. These results indicated that miR-129-5p partially blocks the effect of TGF- $\beta 1$ during the MMT process in HPMCs.

\section{Knockdown of SIP1 or SOX4 Ameliorated TGF- $\beta 1$-Induced MMT/EMT Changes in HPMCs}

To clarify the precise mechanism by which miR-129-5p modulates TGF- $\beta 1$-induced MMT/EMT mRNA and protein expression, SIP1-siRNA and SOX4-siRNA were used to knock a

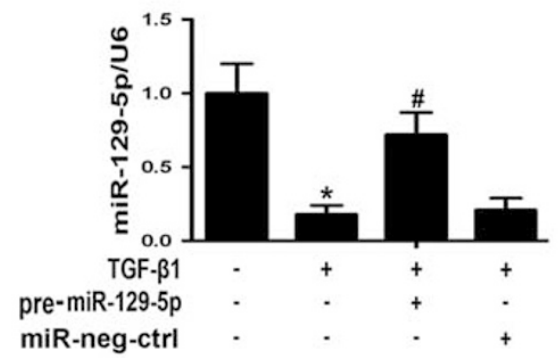

b $\quad B 1$

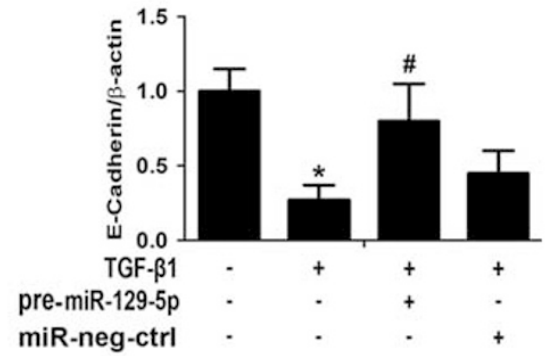

B2

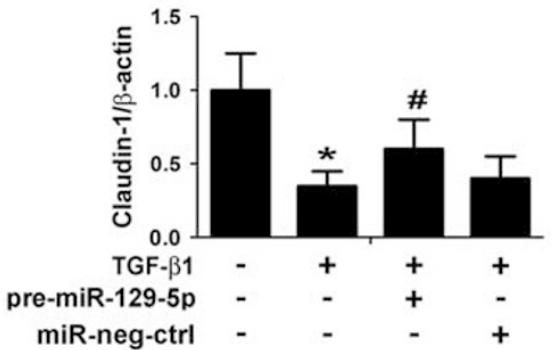

C
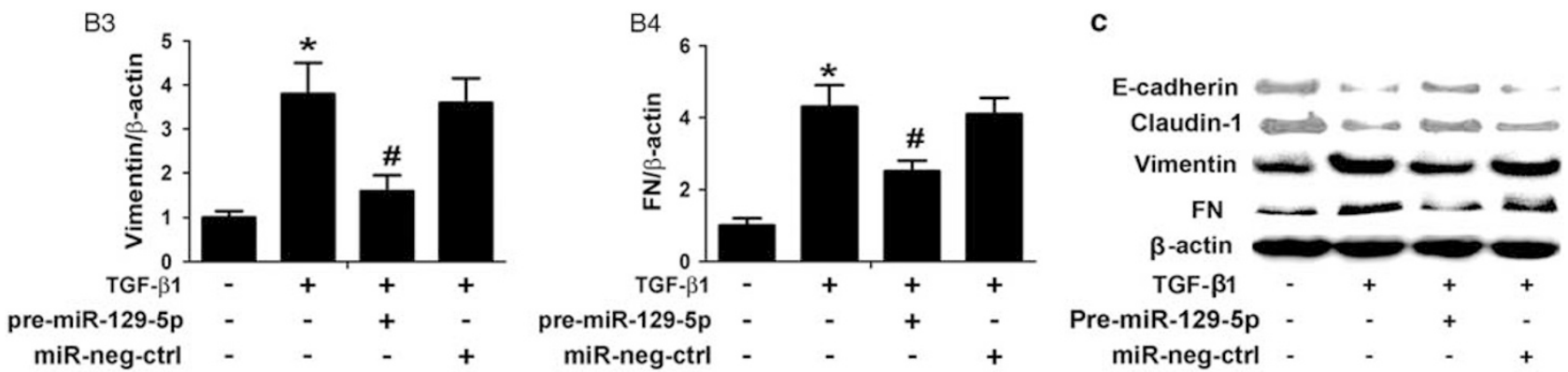

\section{d}
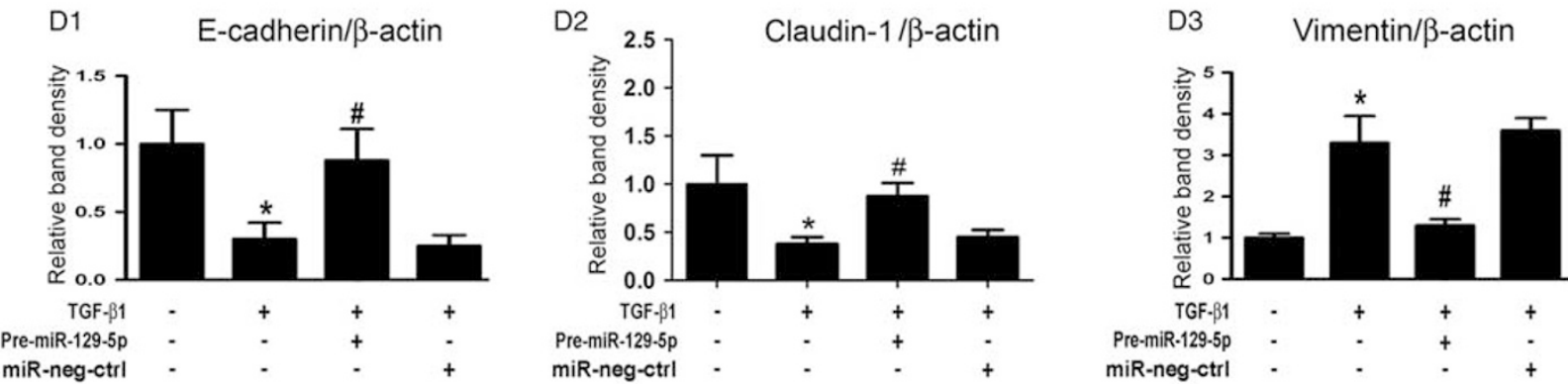

Figure 3 Overexpression of pre-miR-129-5p reverses epithelial-mesenchymal transition-related gene and protein expression in human peritoneal mesothelial cell lines (HPMCs) following treatment with TGF- $\beta$ 1. (a) By real-time PCR, a significantly reduced expression of miR-129-5p with time dependency was observed in HPMCs induced by TGF- $\beta 1(5 \mathrm{ng} / \mathrm{ml})$ for $0-72 \mathrm{~h}$, as compared with control, whereas the effect was abolished in cells transfected with pre-miRNA-129-5p. No effect was seen in cells treated with miR-negative control. The measured transcript level was normalized to U6snRNA expression. (b) Overexpression of miR-129-5p in cells transfected with pre-miR-129-5p reversed the mesenger RNA (mRNA) expression of E-cadherin (B1) and claudin-1 (B2) in TGF- $\beta 1$-induced HPMCs, whereas it partially blocked vimentin (B3) and fibronectin (FN) mRNA (B4) expression, as assessed by real-time PCR analysis. (c) Western blot analysis showed that the protein expression of E-cadherin, claudin-1, vimentin, and FN in TGF- $\beta 1$ stimulated HPMCs with or without transfection with pre-miR-129-5p. The bar graphs represent expression of the above proteins relative to $\beta$-actin (d, D1-D4). (e) Immunofluorescence microscopy showed downregulated E-cadherin and upregulated vimentin expression in HPMCs subjected to TGF- $\beta 1$, which was normalized with transfection with pre-miR-129-5p, and no effect was seen in transfection of miR-neg control. Magnification, $\times 400$. (f) The bar graph represents the density of immunofluorescence intensity of E-cadherin (F1) and vimentin (F2). Values are the mean \pm s.e.m., $n=3,{ }^{*} P<0.01$ vs control, ${ }^{\#} P<0.01$ vs TGF- $\beta 1$. (g) Representative fields of cells showing migration after scratching the HPMC culture and following TGF- $\beta 1$ treatment with or without pre-miR-129-5p transfection. Magnification, $\times 0100$. (h) Quantitative analyses of cell migration in the scratch area. ${ }^{*} P<0.01$ vs control, ${ }^{\#} P<0.01$ vs TGF- $\beta 1$. 


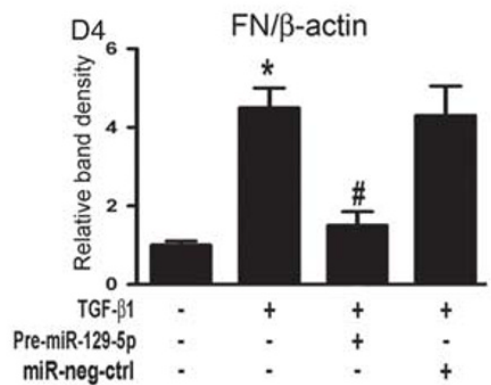

g

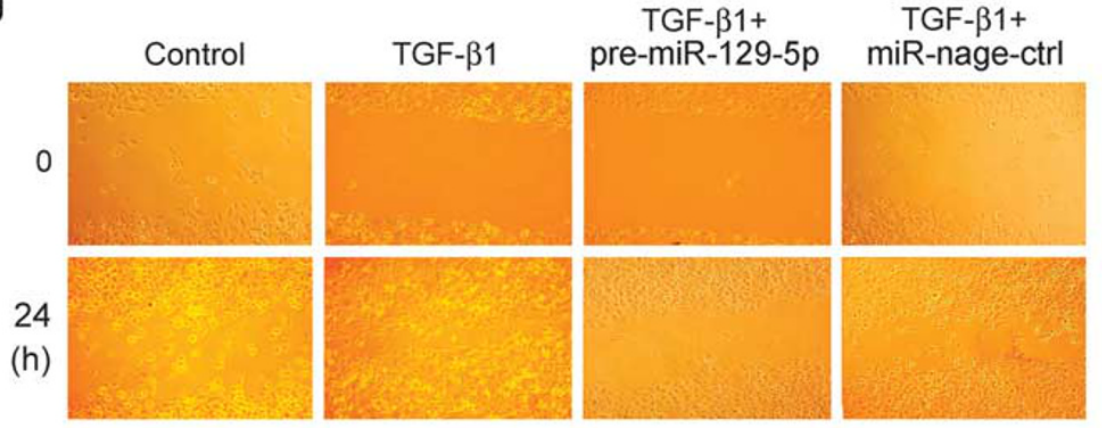

$f$
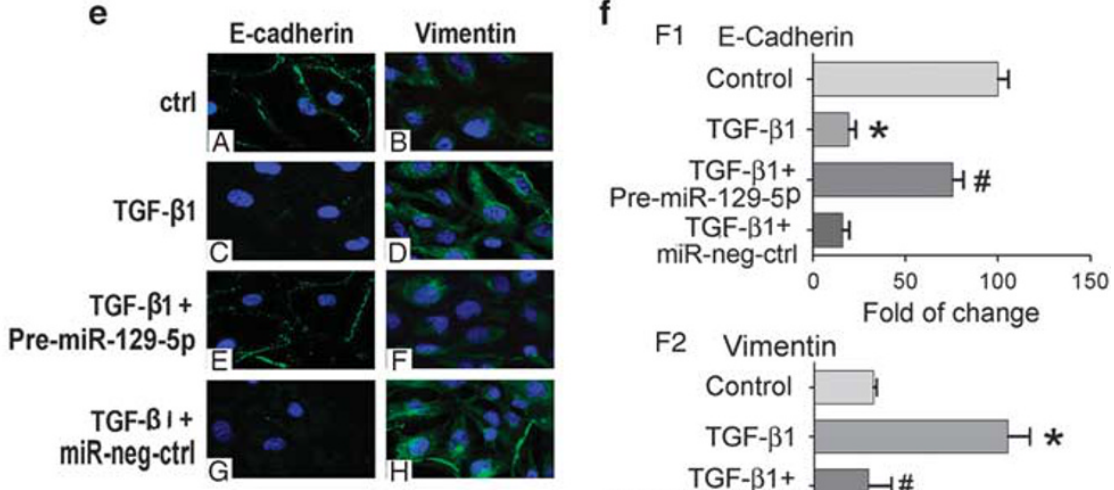

F2 Vimentin Control

TGF- $\beta 1$

TGF- $\beta 1+$

Pre-miR-129-5p

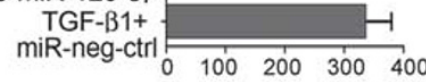

h

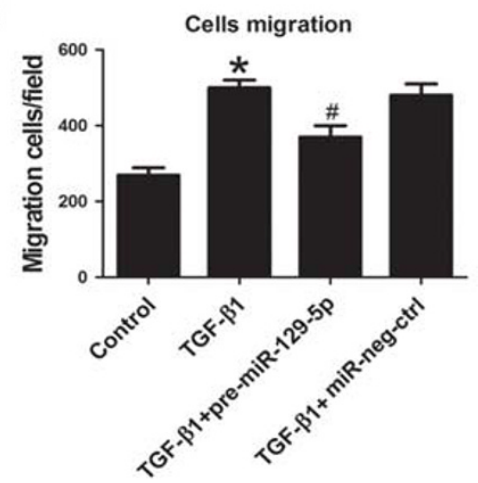

Figure 3 Continued.

down the endogenous expression of SIP1 or SOX4 in HPMCs in vitro. As shown in Figure 4, significantly downregulated mRNA and protein expression of E-cadherin in HPMCs induced by TGF- $\beta 1$ was observed, as demonstrated by realtime PCR and immunoblotting (Figure $4 \mathrm{a} \mathrm{A} 1$ line 2 ss line 1; Figure $4 \mathrm{~b}$ upper panels, Figure $4 \mathrm{c} \mathrm{C} 1$ ). The expression was restored partially by transfection of pre-miR-129-5p or SIP1siRNA (lines 5 and $6 v$ s line 2). In contrast to E-cadherin, the mRNA and protein expression of both vimentin and FN were upregulated in HPMCs stimulated by TGF- $\beta 1$ (Figure 4a A2, line 2 vs line 1, Figure $4 \mathrm{~b}$ middle and Figure $4 \mathrm{c} \mathrm{C} 2$ ), and the expression was inhibited by transfection with pre-miR-129-5p or SIP1-siRNA (lines 5 and 6 vs line 2). This effect was enhanced by co-treatment of pre-miR-129-5p and SIP1siRNA (line $7 v s$ lines 5 and 6). By western blot analysis, a significantly decreased expression of E-cadherin protein in HPMCs treated with TGF- $\beta 1$ or transfected with SIP1 plasmid was seen, and it was reversed by co-treatment with pre-miR-129-5p (Figure 4d D1 upper panel, line 2 and line 4 $v s$ line 1, and Figure $4 \mathrm{~d} \mathrm{D} 2$, left panel). An opposite result was observed for vimentin protein expression (Figure 4d D1 middle panel, and Figure 4d D2, right panel). It is interesting to note that the above changes were also seen in cells transfected with SOX4-siRNA under same conditions (Figure 5a-d). These data suggested that SIP1 and SOX4 probably exert their effects downstream of miR-129-5p and are thus involved in the modulation of MMT-related genes and protein expression in HPMCs induced by TGF- $\beta 1$.

\section{MiR-129-5p Inhibits Protein Expression of SIP1 and SOX4 by Downregulation of their $3^{\prime}$ UTR Activity and Modulation of the Promoter Activity of E-cadherin and Vimentin}

By real-time PCR, a significantly increased mRNA expression of SIP1 and SOX 4 was seen in HPMCs induced by TGF- $\beta 1$ (Figure $6 \mathrm{a}$ and $\mathrm{b}$, line 2 vs line 1), whereas no significant differences were seen between TGF- $\beta 1$ and TGF- $\beta 1+$ miR-129-5p groups (line 3 vs line 2). However, immunostaining with anti-SIP1 or anti-SOX4 antibodies showed that the SIP1 and SOX4 expression in HPMCs increased, which was mainly reflected by a significant increase in the nucleus following treatment with TGF- $\beta 1$. This was significantly dampened by the treatment with pre-miR-129-5p (Figure 6c), whereas treatment with the miR-negative control had no effect. Furthermore, immunoblotting revealed an increased SOX4 and SIP1 protein expression in HPMCs treated with TGF- $\beta 1$ (Figure 6d, line $2 v s$ line 1), whereas it was partially blocked by transfection with pre-miR-129-5p (line $3 v s$ line 2). This 
a

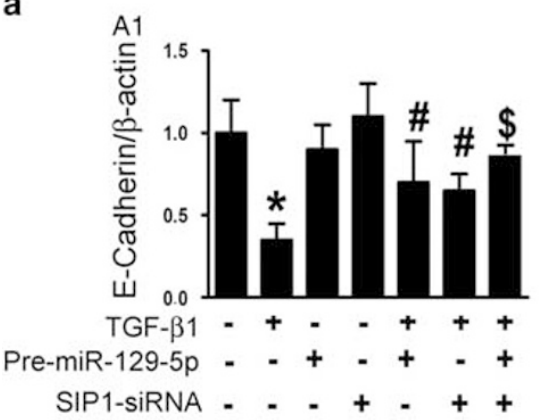

b

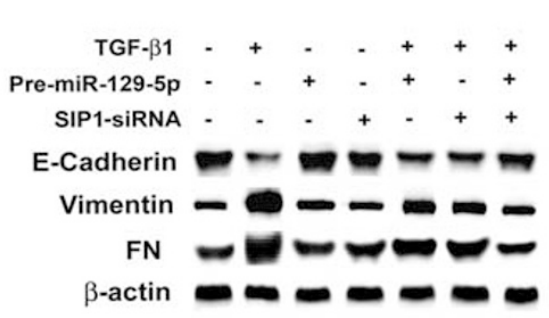

C3

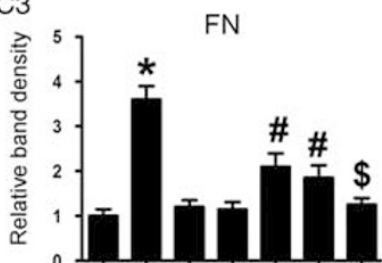

TGF- $\beta 1$ - + - + + +

Pre-miR-129-5p - - + - + +

SIP1-SIRNA - - + +++
A2

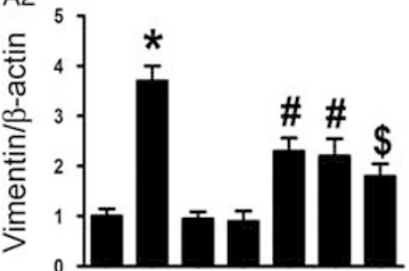

TGF- $\beta 1-+-+++$

Pre-miR-129-5p - - + - + - +

SIP1-SiRNA - - - + - +

C

C1

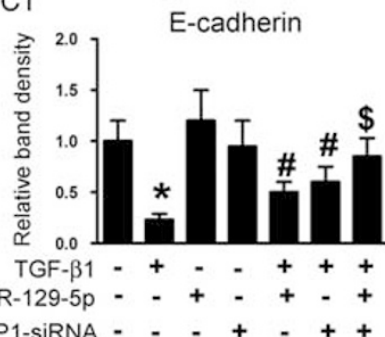

d

D1

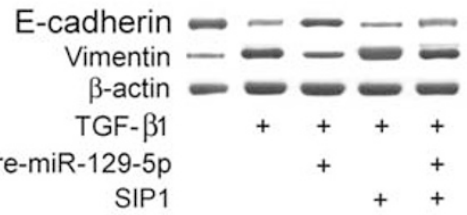

A3

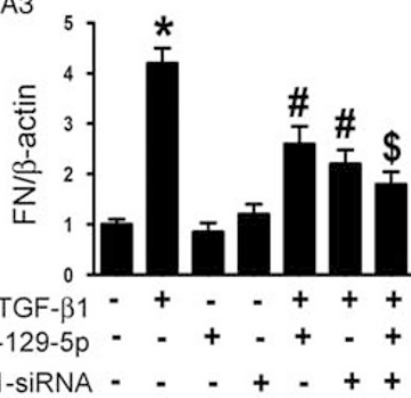

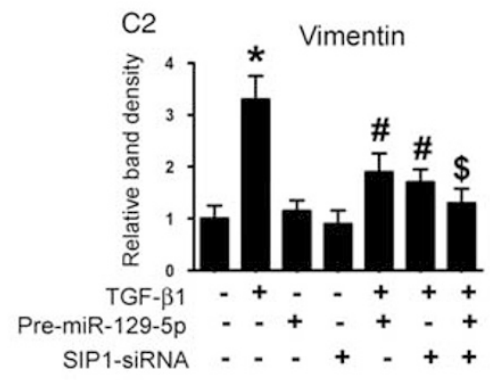

D2

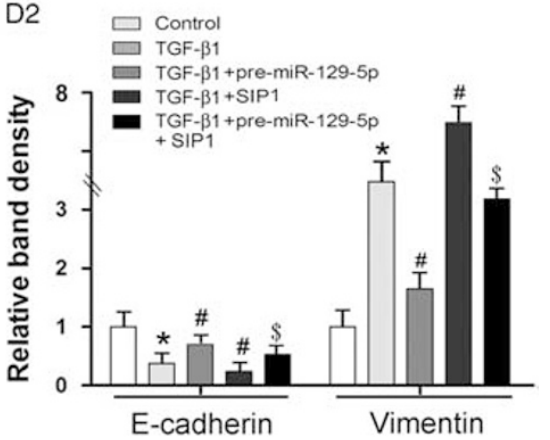

Figure 4 SIP1-siRNA reverses the altered expression of epithelial-mesenchymal transition-related genes in human peritoneal mesothelial cell lines (HPMCs) induced by TGF- $\beta 1$. (a) By real-time PCR, a decreased messenger RNA (mRNA) expression of E-cadherin was seen in HPMCs subjected to TGF$\beta 1$ treatment $(5 \mathrm{ng} / \mathrm{ml})$ for $48 \mathrm{~h}$, whereas it was reversed by transfection with pre-miR-129-5p or SIP1-siRNA. Inhibition of SIP1 expression further enhanced the reversal effect of pre-miR-129-5p in TGF- $\beta 1$-reduced E-cadherin mRNA expression (A1). In addition, compared with E-cadherin expression, an opposite effect was observed for vimentin and fibronectin (FN) mRNA expression (A2, A3). (b) Western blot analysis showed similar results that SIP1siRNA reversed the altered expression of E-cadherin, vimentin, and FN in HPMCs subjected to TGF- $\beta 1$ treatment. The bar graphs represent the densitometric measurements of the relative band density observed by western blot analyses (c, C1-C3). (d, D1) Western blot analysis revealed that overexpression of pre-miR-129-5p partially blocked the altered protein expression of E-cadherin and vimentin in HPMCs treated with TGF- $\beta 1$ or TGF- $\beta 1$ +SIP1. (D2) The bar graphs represent the densitometry measurements of relative band density of autoradiograms of D1. Values are the mean \pm s.e.m., $n=3,{ }^{*} P<0.01$ vs control, $P<0.01$ vs TGF- $\beta 1, P<0.01$ vs ${ }^{\$} P<0.01$ vs TGF- $\beta 1+$ pre-miR-129-5p.

indicated that miR-129-5p repressed the translation of SIP1 and SOX4, but did not cause degradation of their mRNA.

To confirm whether miR-129-5p directly targets the $3^{\prime} \mathrm{UTR}$ of SIP1 or SOX4 gene (5'-CAAAAA- $\left.3^{\prime}\right)$, a 1048-bp fragment of the $3^{\prime}$ UTR of SIP1 and a 786-bp fragment of the $3^{\prime} \mathrm{UTR}$ of SOX4 were cloned into PGL3 luciferase reporter vector. These segments included a predicated binding site for miR-129-5p (Figure 7a). Furthermore, the mutant plasmids with a mutated binding site of miR-129-5p in the 3'UTR of SIP1 and SOX4 were generated and used in the promoter activity analysis. As shown in Figure $7 \mathrm{~b}$ and c, overexpression of pre-miR-129-5p in HPMCs notably decreased the luciferase activity of $3^{\prime} \mathrm{UTR}$ in the wild-type reporter of SIP1 and SOX4 by 36 and 53\%, respectively. However, the activity was not significantly different in cells transfected with the mutant reporter plasmids of SIP1 or SOX4. In addition, there was no effect on the 3'UTR activity following treatment with the miR-negative control.

The promoters of E-cadherin and vimentin contain binding sites for the transcription factor, SIP1. ${ }^{34,36} \mathrm{We}$ therefore tested the E-cadherin promoter activity in HPMCs using a PGL3 luciferase reporter system. As shown 
a

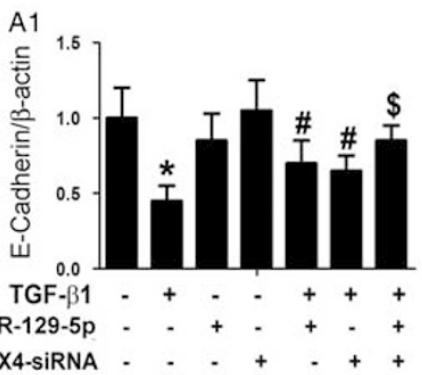

A4

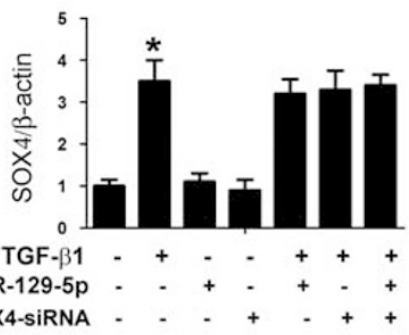

$\mathrm{C} 2$

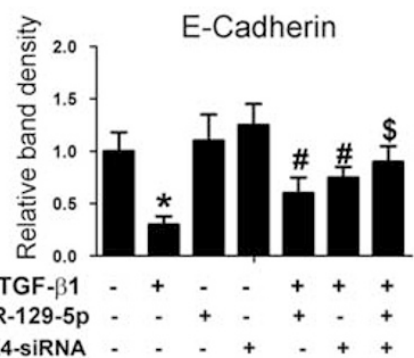

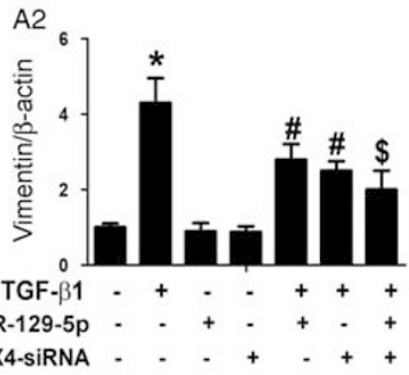

b

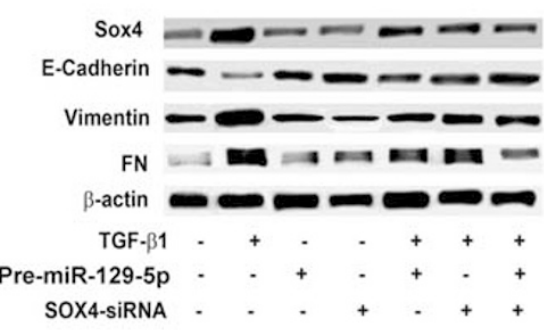

C3

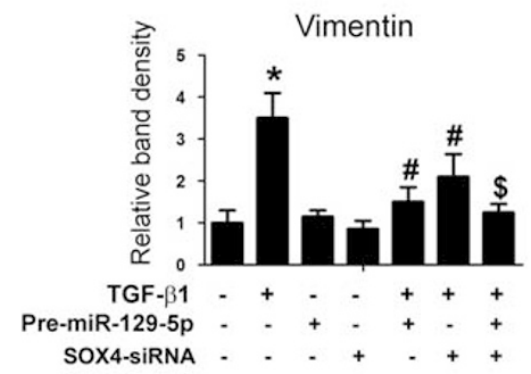

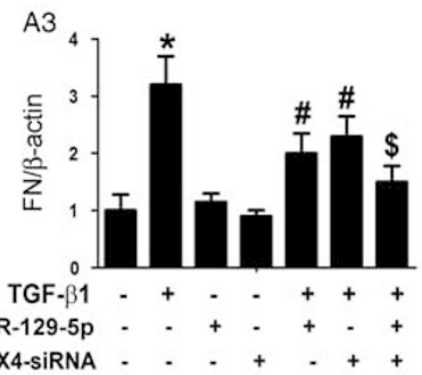

c

C1

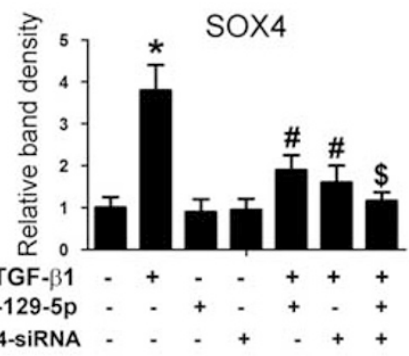

C4

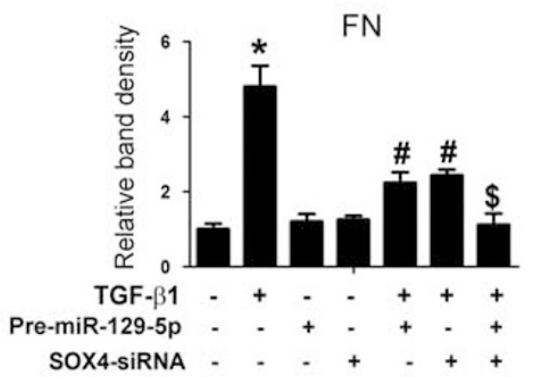

d

D1

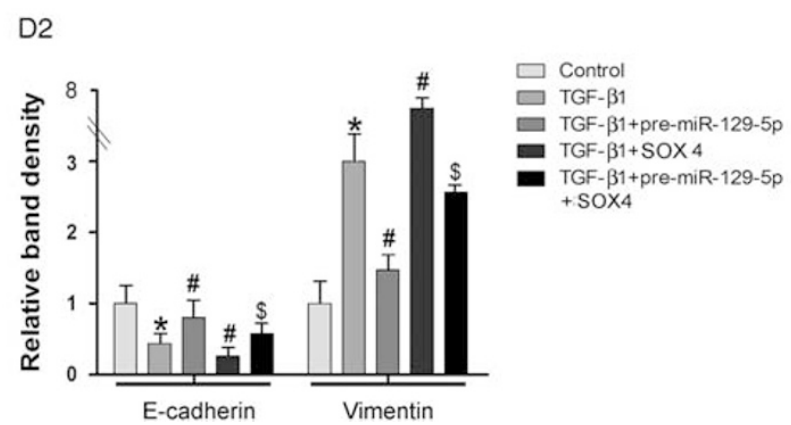

Figure 5 SOX4-siRNA reverses the altered expression of E-cadherin, vimentin, and fibronectin (FN) in human peritoneal mesothelial cell lines (HPMCs) induced by TGF- $\beta 1$. (a, A1) Real-time PCR showed SOX4-siRNA reversed the TGF- $\beta 1$-reduced messenger RNA (mRNA) expression of E-cadherin in HPMCs, whereas this effect was partially blocked in cells transfected with pre-miR-129-5p. In contrast, opposite results were seen for the expression of vimentin and FN mRNA (A2, A3). Furthermore, real-time PCR also revealed that TGF- $\beta 1$ significantly increased SOX4 mRNA expression, whereas there was no change following treatment with pre-miR-129-5p (A4). (b) Western blot analyses revealed comparable results for their protein expression compared with mRNA expression. (c) The bar graphs represent the western blot relative band densities for the SOX4 (C1), E-cadherin(C2), vimentin (C3), and FN (C4) compared with $\beta$-actin. (d, D1) Western blot analyses show that overexpression of pre-miR-129-5p normalizes the altered expression of E-cadherin and vimentin in HPMCs treated with TGF- $\beta 1$ or TGF- $\beta 1+$ SOX4. (D2) The bar graphs represent the protein expression relative band densities of E-cadherin and vimentin compared with $\beta$-actin. Values are the mean \pm s.e.m., $n=3,{ }^{*} P<0.01$ vs control, ${ }^{\#} P<0.01$ vs TGF- $\beta 1, P<0.01$ vs ${ }^{\$} P<0.01$ vs TGF- $\beta 1+$ premiR-129-5p. 
a
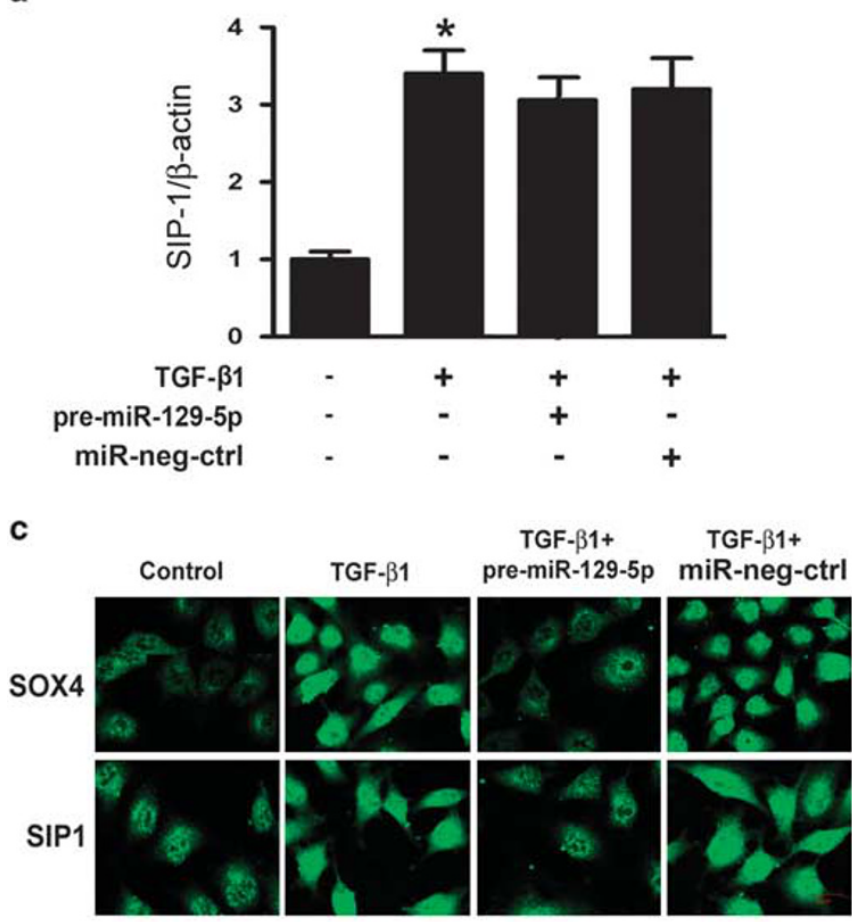

D1

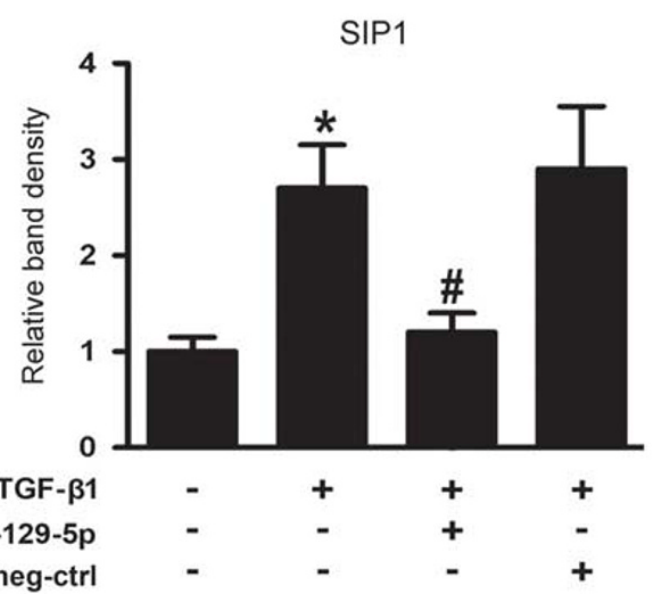

b

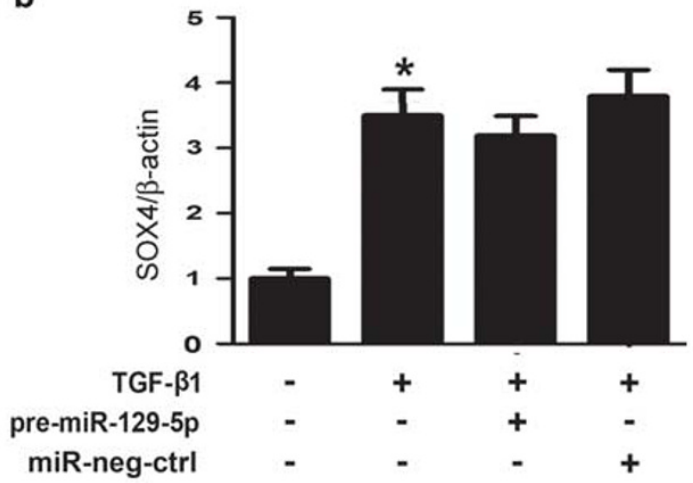

d

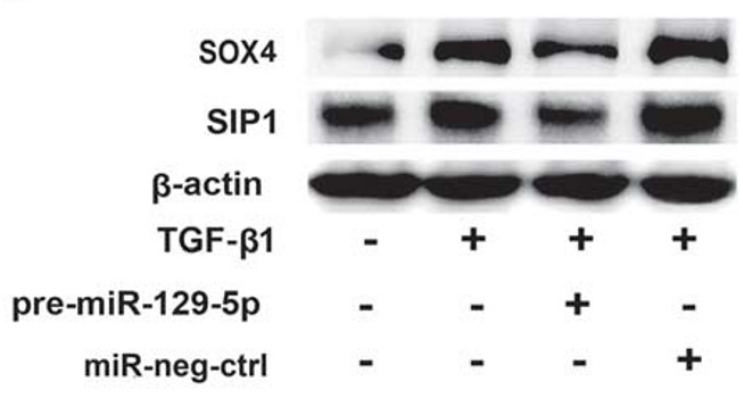

D2

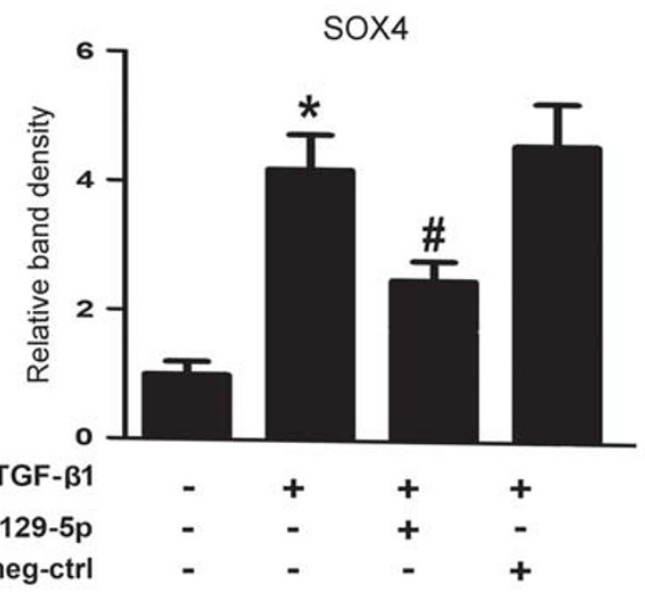

Figure 6 Effect of miR-129-5p on the expression of SIP1 and SOX4 in human peritoneal mesothelial cell lines (HPMCs) treated with TGF- $\beta 1$. (a and b) By real-time PCR, a significant increase in the SIP1 and SOX4 messenger RNA expression in HPMCs subjected to TGF- $\beta 1$ treatment was seen, whereas it was not significantly different between the TGF- $\beta 1$-treated group or group co-treated with TGF- $\beta 1+$ miR-129-5p. (c) Immunofluorescence microscopy revealed an increased SIP1 and SOX4 expression in the nuclei of HPMCs treated with TGF- $\beta 1$, which was normalized with transfection with pre-miR-129-5p. Magnification, $\times 400$. (d) Similar results were observed by western blot assays. (D1, D2) The bar graphs represent the expression of SIP1 and SOX4 protein band densities relative to $\beta$-actin. Values are the mean \pm s.e.m., $n=3,{ }^{*} P<0.01$ vs control, ${ }^{\#} P<0.01$ vs TGF- $\beta 1$.

in Figure 7d, a significantly decreased luciferase activity was observed, which basically represented E-cadherin promoter activity in HPMCs treated with TGF- $\beta 1$ or overexpression of SIP1 (Figure 7d, line 2 and line $4 v s$ line 1). This effect was blocked partially with the pre-treatment of pre-miR-129-5p (line $8 v s$ line 2, line $9 v s$ line 4). Interestingly, opposite results were observed in assays for the vimentin promoter activity (Figure 7e). These results suggest that miR-129-5p modulates E-cadherin and vimentin expression by targeting the $3^{\prime}$ UTR region of SIP1 and SOX4 genes or by modulating the promoter activity of E-cadherin and vimentin by the TGF- $\beta 1 /$ SIP1 pathway.

\section{DISCUSSION}

Recent studies have demonstrated that TGF- $\beta 1$-induced MMT has a central role in the pathogenesis of peritoneal fibrosis in PD. ${ }^{1,16}$ However, the precise mechanism(s) by which TGF- $\beta 1$ induces EMT/MMT process in PD still 

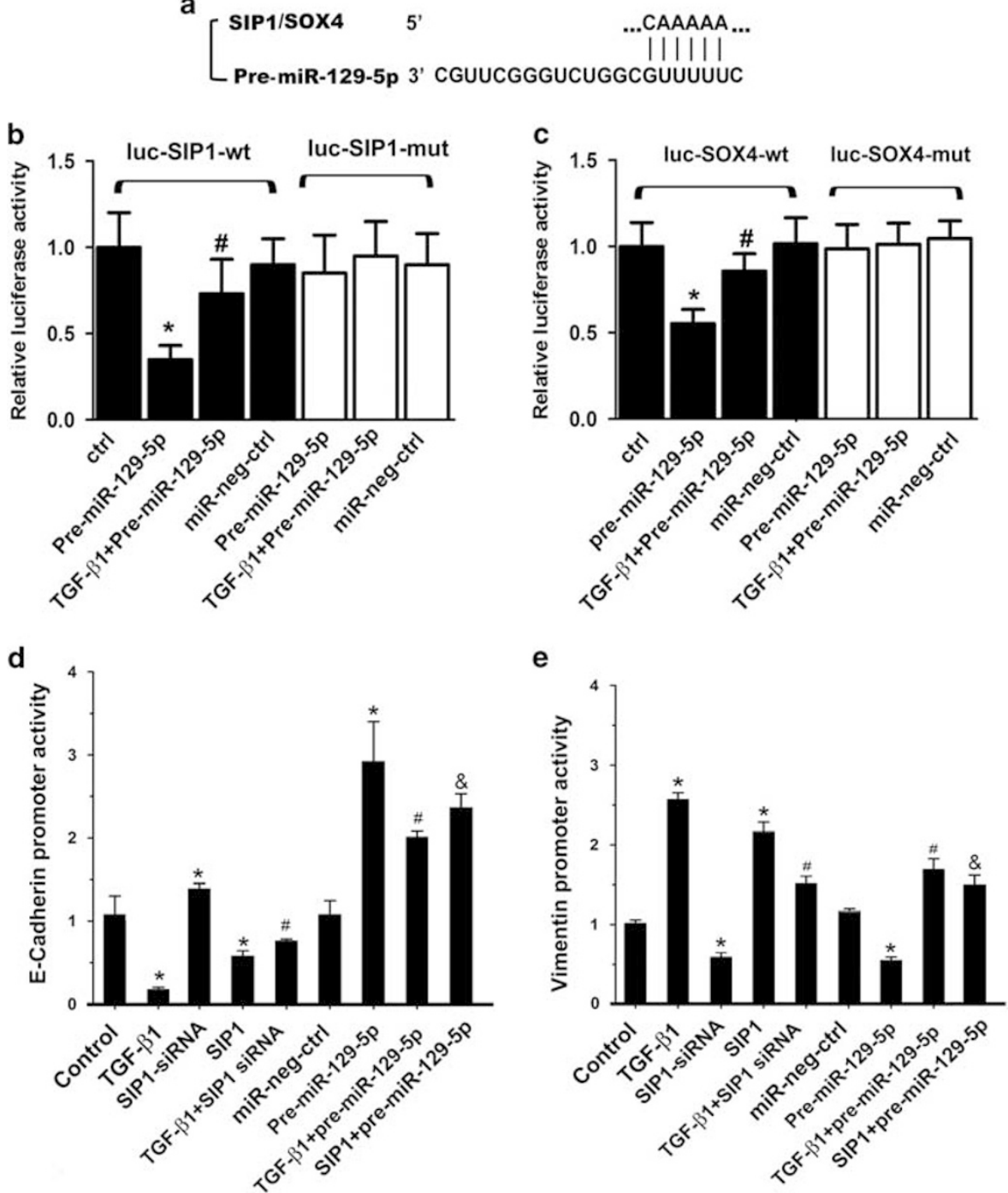

Figure 7 miR-129-5p is predicted to directly target SIP1/SOX4 genes and modulates the promoter activity of both E-cadherin and vimentin in HPMCs. (a) Location of the predicted miR-129-5p target site in SIP1 and SOX4 3'UTR, as assessed by biological analysis (www. microrna.org). (b) A decreased luciferase activity of SIP1-wt in HPMCs treated with pre-miRNA-129-5p while the decreased activity was partially restored with co-treatment of TGF- $\beta$. There was no effect in cells transfected with miR-neg control. (c) Similar results were seen for SOX4 activity. Luciferase activities were normalized to $\beta$-gal activities. Results were obtained from three independent experiments. Data are shown as mean \pm s.e.m. ${ }^{*} P<0.01$ vs control, ${ }^{\#} P<0.01$ vs premiR-129-5p. (d and e) The bar graphs represent luciferase activity in HPMC following various treatments. Opposite effects were observed for the E-cadherin and vimentin promoters. Luciferase activity was normalized with $\beta$-galactosidase activity, and it is depicted as mean value \pm s.e.m. from triplicate measurements. Data are shown as mean \pm s.e.m. ${ }^{*} P<0.01$ vs control, ${ }^{\#} P<0.01$ vs TGF- $\beta 1,{ }^{\&} P<0.05$ vs SIP1.

remains to be clearly defined. In the present study, we identified that the expression of miR-129-5p is decreased both in PD patients and in the HPMCs cell line treated with TGF$\beta 1$, and it negatively correlated with MMT and peritoneal fibrosis. Overexpression of miR-129-5p ameliorated TGF- $\beta 1$ induced MMT, and additionally inhibited cell migration following wound scratch in HPMCs culture. We also investigated the role SIP1 and SOX4, two well-known EMTassociated transcription factors that can directly bind to the promoter E-box site of E-cadherin and vimentin, in the process of MMT in patients undergoing PD. We observed that the inhibition of SIP1 and SOX4, using their respective
siRNA, could dampen EMT by rescuing the altered promoter activity of both the E-cadherin and vimentin in HPMCs following TGF- $\beta 1$ treatment. Our results also indicate that miR-129-5p could directly target the $3^{\prime}$ UTR of SIP1 and SOX4 genes, and repressed their post-translational activities. These data suggest that there is a new pathway of TGF- $\beta 1 /$ miR-129-5p/SIP1 or SOX4 that may have a significant role in the process of MMT and fibrosis in PD.

An emerging body of evidence suggests that miRNAs are dysregulated and they mediate the TGF- $\beta$-induced EMT process in various neoplastic processes. ${ }^{37-40}$ With respect to peritoneal fibrosis, we reported that miRNA589 is decreased 
and it negatively regulates EMT in cultured human PMCs treated with TGF- $\beta 1$ (ref. 10), and likewise, Zhou Q et al. reported that another miRNA, miR30a, ameliorates TGF- $\beta 1$ induced EMT and peritoneal fibrosis by targeting snaill. This suggests that miRNAs may have a key role in peritoneal fibrosis of PD. To comprehensively study the role of miRNAs, their expression profile in PD state was carried out along with in vitro studies, using PMCs, where the process of MMT was investigated following TGF- $\beta 1$ treatment. As shown in Figure 1 and Tables 2 and 3,33 miRNAs were upregulated and 58 miRNAs were downregulated in patients having PD over 6 months compared with the patients of the PD-start group. Among those downregulated, the expression of miR-129-5p was noted to be significantly decreased. This change in the expression was confirmed by northern blot analyses and real-time PCR in effluents of patients with PD $>6$ months, as well as in HPMCs treated with TGF- $\beta 1$ (Figure 2). Recent studies have shown that downregulation of miR-129-5p expression was mediated by blocking the IL-17A receptor in fibroblasts following the TGF- $\beta 1$ treatment, ${ }^{20}$ suggesting that decreased miR-129-5p in PD may be modulated by the TGF- $\beta 1 / \mathrm{IL}-17 \mathrm{~A}$ pathway. The miR-129-5p is one of the mature forms of miR-129-1 and miR-129-2, and previous studies have shown that miR-129, especially the miR-129-5p, has a vital role in various neoplastic processes where it serves as a tumor suppressor. ${ }^{13,18,19,41}$ Interestingly, it is also known that the expression of miR-129-5p is downregulated in states of fibrosis, such as, systemic sclerosis where it modulates the collagen I expression ${ }^{20}$ and also under circumstances where invasion/migration of cells is affected, such as, in thyroid carcinoma cells. ${ }^{42}$ This would suggest that miR-129-5p has a potential role in regulating the EMT process and fibrosis. However, whether miR-129-5p is involved in peritoneal fibrosis during PD is unknown. Thus, we selected the miRNA-129-5p for the investigation in this study among various miRNAs that were detected during expression profiling.

In this study, we discovered that expression of miR-129-5p is significantly downregulated in both MCs isolated from the effluent of PD or HPMCs cells treated with TGF- $\beta 1$. This change was associated with decreased expression of E-cadherin and claudin- 1 and increased expression of vimentin and FN (Figures 1 and 2). On the other hand, overexpression of miR-129-5p markedly reversed the effect of TGF- $\beta 1$-induced expression of EMT-related genes and protein expression (Figure 3), suggesting that miR-129-5p acts as a negative modulator during the process of MMT that is induced by TGF- $\beta 1$ in PD.

There are many transcription factors and pathways involved in the TGF- $\beta 1$-induced EMT process, such as ZEB1, ${ }^{43}$ SIP $1,{ }^{44}$ snail,${ }^{45}$ slug, ${ }^{46}$ SOX $4,{ }^{47}$ Jagged/Notch, ${ }^{48}$ and the Wnt $3 \mathrm{a} / \beta$-catenin wnt $/ \beta$-cat pathway. ${ }^{49}$ To delineate the mechanism by which miR-129-5p modulates TGF- $\beta 1$-induced MMT gene expression in $\mathrm{PD}$, we focused to investigate the status of SIP1 and SOX4. The SIP1, also known as ZEB2, is thought to be a transcription factor that acts as a repressor by binding to two widely separated clusters of $\mathrm{c} 2 \mathrm{H} 2$-type zinc fingers and paired CAGGTA/G E-box-like promoter elements of E-cadherin and vimentin genes. Conceivably, SIP1 could also induce the TGF- $\beta$-stimulated EMT process by suppressing the expression of many genes characteristic of epithelia $27,50,51$ and also through targeting miR-132, miR-205, and miR-200 to ultimately regulate the EMT process. ${ }^{50,52-54}$ Moreover, SIP1 is also known to coordinate miR-200a-3p/141-3p to induce renal mesangial cells to undergo $\mathrm{EMT}^{43,55}$ while it can also regulate E-cadherin expression utilizing miR-192/215. ${ }^{56}$

SOX4 modulates transcription responses to TGF- $\beta 1$, Wnt signaling, Notch pathway, and various miRNA processing. ${ }^{57-60}$ SOX 4 is a downstream target of TGF- $\beta 1$ (ref. 61) and have been shown to mediate the TGF- $\beta$-induced EMT process in mammary cells. ${ }^{47}$ Moreover, many studies suggest that SOX4 is a downstream of miR-129-5 $\mathrm{p}^{47,61-63}$ and the SOX4 $3^{\prime}$ UTR is one of the targets of miR-129-5p. ${ }^{18,19,42,64}$ Interestingly, Sand (Sp100, AIRE-1, NucP41/75, DEAF-1) epigenetic repression of miRNA-129 leads to overexpression of SOX4 in certain neoplastic processes. ${ }^{63}$ Furthermore, biological software analyses indicate that miRNA-129-5p target genes include SIP1 and SOX4, and not others like snail1 and snail3, etc (www.microrna org; www.targetscan.org). This information suggests that SIP1 and SOX4 may have a critical role, unlike the other downstream molecules, such as ZEB1 and snaill, etc. In this scenario, they would conceivably participate in the TGF- $\beta 1$-induced EMT process and fibrosis by interacting with miRNA-129-5p in states of PD. In view of this, we investigated the effect of SIP1 and SOX4 in TGF- $\beta 1$ induced EMT modulated by miR-129-5p.

Our findings indicate that expression of SIP1 significantly increased in HPMCs both in patients undergoing PD patients and cells treated with TGF- $\beta 1$. This upregulation tightly correlated with the expression of EMT-related genes and protein, and negatively correlated with the expression of miR-129-5p (Figures 1 and 2). In addition, we observed that inhibiting SIP1 expression with its siRNA blocked MMT induced by TGF- $\beta 1$ in vitro (Figure 4 ). In contrast, overexpression of miR-129-5p decreased the mRNA and protein expression of SIP1 (Figure 6). These data suggest that SIP1 may serve as a critical modulator of miR-129-5p in the MMT process during $\mathrm{PD}$. We also observed that expression of SOX4 increased in PMCs isolated from PD patients and HPMCs cell lines stimulated by TGF- $\beta 1$, and it negatively correlated with the expression of miR-129-5p and MMT changes (Figures 1 and 2). Similar to SIP1, SOX4-siRNA also blocked the MMT induced by TGF- $\beta 1$ in vitro (Figure 5 ). Overexpression of miR-129-5p decreased the protein expression of SOX4 (Figure 6), suggesting that both SIP1 and SOX4 can serve as the key downstream molecules utilizing different pathways but ultimately converging into TGF- $\beta 1 / \mathrm{miR}-129-5 \mathrm{p}$ pathway that modulated EMT/MMT process in PD.

This study also demonstrates that TGF- $\beta 1$ and SIP1 independently confer a repression of E-cadherin expression by 
inhibiting its promoter activity, as assessed by luciferase activity analysis (Figure 7a). In contrast to E-cadherin, an increased promoter activity of vimentin was observed (Figure $7 \mathrm{~b}$ ), and these perturbations in the activities were reversed by the treatment with pre-miR-129-59. Incidentally, it has been reported that miR-129 directly targets SOX4 as indicated by the $3^{\prime}$ UTR analysis. ${ }^{62,63}$ Likewise, we noted that miR-129-5p directly interacts with the 3hUTR of SIP1 and SOX4, and overexpression of pre-miR-129-5p decreased the luciferase activity of the 3'UTR wild-type reporter of SIP1 and SOX4. However, no effect was observed in the mutant of $3^{\prime}$ UTR reporter of SIP1 or SOX4 (Figure 7c and d), suggesting that miR-129-5p exerts a protective role in MMT in PD, which may be partly through the downstream SIP1 and SOX4 transcription factors.

In summary, we suggest that miR-129-5p is a critical molecule in protection of MCs undergoing MMT transformation induced by TGF- $\beta 1$ during of PD. Our findings also suggest that miR-129-5p exerts its protective effect perhaps through direct targeting of SIP1 and SOX4. Finally, it is anticipated that these findings may provide new insights into the role of miR-129-5p in the MMT and peritoneal fibrosis in $\mathrm{PD}$, and yield an opportunity for developing novel therapeutic interventions.

\section{ACKNOWLEDGMENTS}

This work was supported by the Natural Sciences Foundation of China (81100541, 81370832, 81270812, 81470960 and 81300600), the Doctoral Fund of Ministry of Education of China (20110162110012), Furong Scholars Fund from Hunan Province Education Department and the NIH Grant (DK60635).

\section{DISCLOSURE/CONFLICT OF INTEREST}

The authors declare no conflict of interest.

1. Loureiro J, Gonzalez-Mateo G, Jimenez-Heffernan J et al. Are the mesothelial-to-mesenchymal transition, sclerotic peritonitis syndromes, and encapsulating peritoneal sclerosis part of the same process? Int J Nephrol 2013;2013:263285.

2. Perez-Lozano ML, Sandoval P, Rynne-Vidal A et al. Functional relevance of the switch of VEGF receptors/co-receptors during peritoneal dialysis-induced mesothelial to mesenchymal transition. PLoS One 2013;8:e60776.

3. Del Peso G, Jimenez-Heffernan JA, Bajo MA et al. Epithelial-tomesenchymal transition of mesothelial cells is an early event during peritoneal dialysis and is associated with high peritoneal transport. Kidney Int Suppl 2008;108:S26-S33.

4. Mizutani $M$, Ito $Y$, Mizuno $M$ et al. Connective tissue growth factor (CTGF/CCN2) is increased in peritoneal dialysis patients with high peritoneal solute transport rate. Am J Physiol Renal Physiol 2010;298: F721-F733.

5. Aroeira LS, Aguilera A, Sanchez-Tomero JA et al. Epithelial to mesenchymal transition and peritoneal membrane failure in peritoneal dialysis patients: pathologic significance and potential therapeutic interventions. J Am Soc Nephrol 2007;18:2004-2013.

6. Margetts PJ, Bonniaud P. Basic mechanisms and clinical implications of peritoneal fibrosis. Perit Dial Int 2003;23:530-541.

7. Shi Y, Massague J. Mechanisms of TGF-beta signaling from cell membrane to the nucleus. Cell 2003;113:685-700.

8. $\mathrm{Xu} \mathrm{J,} \mathrm{Lamouille} \mathrm{S,} \mathrm{Derynck} \mathrm{R.} \mathrm{TGF-beta-induced} \mathrm{epithelial} \mathrm{to}$ mesenchymal transition. Cell Res 2009;19:156-172.

9. Desmouliere A, Geinoz A, Gabbiani F et al. Transforming growth factorbeta 1 induces alpha-smooth muscle actin expression in granulation tissue myofibroblasts and in quiescent and growing cultured fibroblasts. J Cell Biol 1993;122:103-111.

10. Zhang $\mathrm{K}$, Zhang $\mathrm{H}$, Zhou $\mathrm{X}$ et al. miRNA589 regulates epithelialmesenchymal transition in human peritoneal mesothelial cells. J Biomed Biotechnol 2012;2012:673096.

11. Liu $Q$, Mao H, Nie J et al. Transforming growth factor $\{$ beta\}1 induces epithelial-mesenchymal transition by activating the JNK-Smad3 pathway in rat peritoneal mesothelial cells. Perit Dial Int 2008;28: S88-S95.

12. Jang $\mathrm{YH}$, Shin $\mathrm{HS}$, Sun Choi $\mathrm{H}$ et al. Effects of dexamethasone on the TGF-beta1-induced epithelial-to-mesenchymal transition in human peritoneal mesothelial cells. Lab Invest 2013;93:194-206.

13. Yu X, Luo L, Wu Y et al. Gastric juice miR-129 as a potential biomarker for screening gastric cancer. Med Oncol 2013;30:365.

14. Ambros V. The functions of animal microRNAs. Nature 2004;431: 350-355.

15. Jiang $X$, Tsitsiou E, Herrick SE et al. MicroRNAs and the regulation of fibrosis. FEBS J 2010;277:2015-2021.

16. Zhou $\mathrm{Q}$, Yang $\mathrm{M}$, Lan $\mathrm{H}$ et al. miR-30a negatively regulates TGF-beta1induced epithelial-mesenchymal transition and peritoneal fibrosis by targeting Snai1. Am J Pathol 2013;183:808-819.

17. Yu JW, Duan WJ, Huang XR et al. MicroRNA-29b inhibits peritoneal fibrosis in a mouse model of peritoneal dialysis. Lab Invest 2014;94: 978-990.

18. Yu X, Song H, Xia T et al. Growth inhibitory effects of three miR-129 family members on gastric cancer. Gene 2013;532:87-93.

19. Li M, Tian L, Wang $L$ et al. Down-regulation of miR-129-5p inhibits growth and induces apoptosis in laryngeal squamous cell carcinoma by targeting APC. PLoS One 2013;8:e77829.

20. Nakashima T, Jinnin M, Yamane $\mathrm{K}$ et al. Impaired IL-17 signaling pathway contributes to the increased collagen expression in scleroderma fibroblasts. J Immunol 2012;188:3573-3583.

21. Al-Malki HA, Fawzy AA, Rashid $\mathrm{AH}$ et al. Standard continuous ambulatory peritoneal dialysis therapy provides similar initial T-Kt/V regardless of the patient's peritoneal membrane transporter category: single-center experience. Saudi J Kidney Dis Transpl 2014;25: 788-792.

22. Vazquez-Rangel A, Soto V, Escalona $M$ et al. Spironolactone to prevent peritoneal fibrosis in peritoneal dialysis patients: a randomized controlled trial. Am J Kidney Dis 2014;63:1072-1074.

23. Rougier JP, Guia S, Hagege J et al. PAl-1 secretion and matrix deposition in human peritoneal mesothelial cell cultures: transcriptional regulation by TGF-beta 1. Kidney Int 1998;54:87-98.

24. Rougier JP, Moullier P, Piedagnel R et al. Hyperosmolality suppresses but TGF beta 1 increases MMP9 in human peritoneal mesothelial cells. Kidney Int 1997;51:337-347.

25. Lin S, Sahai A, Chugh SS et al. High glucose stimulates synthesis of fibronectin via a novel protein kinase C, Rap1b, and B-Raf signaling pathway. J Biol Chem 2002;277:41725-41735.

26. Zhang $D$, Sun $L$, Xian $W$ et al. Low-dose paclitaxel ameliorates renal fibrosis in rat UUO model by inhibition of TGF-beta/Smad activity. Lab Invest 2010;90:436-447.

27. Lindley LE, Briegel KJ. Molecular characterization of TGFbeta-induced epithelial-mesenchymal transition in normal finite lifespan human mammary epithelial cells. Biochem Biophys Res Commun 2010;399: 659-664.

28. Kato $M$, Zhang J, Wang $M$ et al. MicroRNA-192 in diabetic kidney glomeruli and its function in TGF-beta-induced collagen expression via inhibition of E-box repressors. Proc Natl Acad Sci USA 2007;104: 3432-3437.

29. Kang M, Li Y, Liu W et al. miR-129-2 suppresses proliferation and migration of esophageal carcinoma cells through downregulation of SOX4 expression. Int J Mol Med 2013;32:51-58.

30. Long J, Wang $\mathrm{Y}$, Wang $\mathrm{W}$ et al. MicroRNA-29c is a signature microRNA under high glucose conditions that targets Sprouty homolog 1, and its in vivo knockdown prevents progression of diabetic nephropathy. J Biol Chem 2011;286:11837-11848.

31. Sun L, Zhang D, Liu F et al. Low-dose paclitaxel ameliorates fibrosis in the remnant kidney model by down-regulating miR-192. J Pathol 2011;225:364-377.

32. Yu L, Ding GF, He C et al. MicroRNA-424 is down-regulated in hepatocellular carcinoma and suppresses cell migration and invasion through c-Myb. PLoS One 2014;9:e91661. 
33. Li F, Li S, Cheng T. TGF-beta1 promotes osteosarcoma cell migration and invasion through the miR-143-versican pathway. Cell Physiol Biochem 2014;34:2169-2179.

34. Miyoshi A, Kitajima Y, Sumi K et al. Snail and SIP1 increase cance invasion by upregulating MMP family in hepatocellular carcinoma cells. Br J Cancer 2004;90:1265-1273.

35. Rittling SR, Baserga R. Functional analysis and growth factor regulation of the human vimentin promoter. Mol Cell Biol 1987;7: 3908-3915.

36. Bindels S, Mestdagt M, Vandewalle $C$ et al. Regulation of vimentin by SIP1 in human epithelial breast tumor cells. Oncogene 2006;25: 4975-4985.

37. Jiang Z, Yin J, Fu W et al. MiRNA 17 family regulates cisplatin-resistant and metastasis by targeting TGFbetaR2 in NSCLC. PLoS One 2014;9: e94639.

38. Kitamura K, Seike M, Okano T et al. MiR-134/487b/655 cluster regulates TGF-beta-induced epithelial-mesenchymal transition and drug resistance to gefitinib by targeting MAGI2 in lung adenocarcinoma cells. Mol Cancer Ther 2014;13:444-453.

39. Sun Y, Shen S, Liu X et al. MiR-429 inhibits cells growth and invasion and regulates EMT-related marker genes by targeting Onecut2 in colorectal carcinoma. Mol Cell Biochem 2014;390:19-30.

40. Taylor MA, Davuluri G, Parvani JG et al. Upregulated WAVE3 expression is essential for TGF-beta-mediated EMT and metastasis of triplenegative breast cancer cells. Breast Cancer Res Treat 2013;142: 341-353.

41. Brest $P$, Lassalle $S$, Hofman V et al. MiR-129-5p is required for histone deacetylase inhibitor-induced cell death in thyroid cancer cells. Endocr Relat Cancer 2011;18:711-719.

42. Duan L, Hao X, Liu Z et al. MiR-129-5p is down-regulated and involved in the growth, apoptosis and migration of medullary thyroid carcinoma cells through targeting RET. FEBS Lett 2014;588:1644-1651.

43. Gao J, Zhu Y, Nilsson M et al. TGF-beta isoforms induce EMT independent migration of ovarian cancer cells. Cancer Cell Int 2014;14:72.

44. Gregory PA, Bert AG, Paterson EL et al. The miR-200 family and miR-205 regulate epithelial to mesenchymal transition by targeting ZEB1 and SIP1. Nat Cell Biol 2008;10:593-601.

45. Chen XH, Liu ZC, Zhang G et al. TGF-beta and EGF induced HLA-I downregulation is associated with epithelial-mesenchymal transition (EMT) through upregulation of snail in prostate cancer cells. Mol Immunol 2015;65:34-42.

46. Wang Y, Shi J, Chai K et al. The Role of Snail in EMT and tumorigenesis. Curr Cancer Drug Targets 2013;13:963-972.

47. Vervoort SJ, Lourenco AR, van Boxtel R et al. SOX4 mediates TGF-betainduced expression of mesenchymal markers during mammary cell epithelial to mesenchymal transition. PLoS One 2013;8:e53238.

48. Chen X, Xiao W, Liu X et al. Blockade of Jagged/Notch pathway abrogates transforming growth factor beta2-induced epithelialmesenchymal transition in human retinal pigment epithelium cells. Curr Mol Med 2014;14:523-534.
49. Zou W, Zou Y, Zhao Z et al. Nicotine-induced epithelial-mesenchymal transition via Wnt/beta-catenin signaling in human airway epithelial cells. Am J Physiol Lung Cell Mol Physiol 2013;304:L199-L209.

50. Brabletz S, Brabletz T. The ZEB/miR-200 feedback loop-a motor of cellular plasticity in development and cancer? EMBO Rep 2010;11:670-677.

51. Vandewalle C, Van Roy F, Berx G. The role of the ZEB family of transcription factors in development and disease. Cell Mol Life Sci 2009;66:773-787

52. You J, Li $\mathrm{Y}$, Fang $\mathrm{N}$ et al. MiR-132 suppresses the migration and invasion of lung cancer cells via targeting the EMT regulator ZEB2. PLoS One 2014;9:e91827.

53. Lee JY, Park MK, Park JH et al. Loss of the polycomb protein Mel-18 enhances the epithelial-mesenchymal transition by ZEB1 and ZEB2 expression through the downregulation of miR-205 in breast cancer. Oncogene 2014;33:1325-1335.

54. Kim T, Veronese A, Pichiorri $F$ et al. p53 regulates epithelialmesenchymal transition through microRNAs targeting ZEB1 and ZEB2. J Exp Med 2011;208:875-883.

55. Wei J, Zhang Y, Luo $Y$ et al. Aldose reductase regulates miR-200a-3p/ 141-3p to coordinate Keap1-Nrf2, Tgfbeta1/2, and Zeb1/2 signaling in renal mesangial cells and the renal cortex of diabetic mice. Free Radic Biol Med 2014;67:91-102.

56. Wang $B$, Herman-Edelstein $M$, Koh $\mathrm{P}$ et al. E-cadherin expression is regulated by miR-192/215 by a mechanism that is independent of the profibrotic effects of transforming growth factor-beta. Diabetes 2010;59:1794-1802.

57. Medina PP, Castillo SD, Blanco S et al. The SRY-HMG box gene, SOX4, is a target of gene amplification at chromosome $6 p$ in lung cancer. Hum Mol Genet 2009;18:1343-1352.

58. Tavazoie SF, Alarcon C, Oskarsson $\mathrm{T}$ et al. Endogenous human microRNAs that suppress breast cancer metastasis. Nature 2008;451: 147-152.

59. Sinner D, Kordich JJ, Spence JR et al. Sox17 and Sox4 differentially regulate beta-catenin/T-cell factor activity and proliferation of colon carcinoma cells. Mol Cell Biol 2007;27:7802-7815.

60. Scharer CD, McCabe CD, Ali-Seyed $M$ et al. Genome-wide promoter analysis of the SOX4 transcriptional network in prostate cancer cells. Cancer Res 2009;69:709-717.

61. Kuwahara M, Yamashita M, Shinoda $\mathrm{K}$ et al. The transcription factor Sox4 is a downstream target of signaling by the cytokine TGF-beta and suppresses $\mathrm{T}(\mathrm{H}) 2$ differentiation. Nat Immunol 2012;13:778-786.

62. Shen R, Pan S, Qi $S$ et al. Epigenetic repression of microRNA-129-2 leads to overexpression of SOX4 in gastric cancer. Biochem Biophys Res Commun 2010;394:1047-1052.

63. Huang YW, Liu JC, Deatherage DE et al. Epigenetic repression of microRNA-129-2 leads to overexpression of SOX4 oncogene in endometrial cancer. Cancer Res 2009;69:9038-9046.

64. Zhang J, Li S, Yan Q et al. Interferon-beta induced microRNA-129-5p down-regulates HPV-18 E6 and E7 viral gene expression by targeting SP1 in cervical cancer cells. PLoS One 2013;8:e81366. 